\title{
A structure-activity relationship linking non-planar PCBs to functional deficits of neural crest cells: new roles for connexins
}

\author{
Johanna Nyffeler ${ }^{1,2} \cdot$ Petra Chovancova ${ }^{1,3} \cdot$ Xenia Dolde $^{1,3} \cdot$ Anna-Katharina Holzer $^{1} \cdot$ Vladimir Purvanov $^{4}$. \\ Ilona Kindinger ${ }^{4} \cdot$ Anna Kerins $^{5}$. David Higton ${ }^{5}$. Steve Silvester ${ }^{5}$ - Barbara M. A. van Vugt-Lussenburg ${ }^{6}$. \\ Enrico Glaab ${ }^{7}$. Bart van der Burg ${ }^{6} \cdot$ Richard Maclennan $^{5} \cdot$ Daniel F. Legler $^{2,3,4} \cdot$ Marcel Leist $^{1,2,3}$
}

Received: 12 August 2017 / Accepted: 15 November 2017 / Published online: 21 November 2017

C) Springer-Verlag GmbH Germany, part of Springer Nature 2017

\begin{abstract}
Migration of neural crest cells (NCC) is a fundamental developmental process, and test methods to identify interfering toxicants have been developed. By examining cell function endpoints, as in the 'migration-inhibition of NCC (cMINC)' assay, a large number of toxicity mechanisms and protein targets can be covered. However, the key events that lead to the adverse effects of a given chemical or group of related compounds are hard to elucidate. To address this issue, we explored here, whether the establishment of two overlapping structure-activity relationships (SAR)—linking chemical structure on the one hand to a phenotypic test outcome, and on the other hand to a mechanistic endpoint—was useful as strategy to identify relevant toxicity mechanisms. For this purpose, we chose polychlorinated biphenyls (PCB) as a large group of related, but still toxicologically and physicochemically diverse structures. We obtained concentration-dependent data for 26 PCBs in the cMINC assay. Moreover, the test chemicals were evaluated by a new high-content imaging method for their effect on cellular re-distribution of connexin43 and for their capacity to inhibit gap junctions. Non-planar PCBs inhibited NCC migration. The potency $(1-10 \mu \mathrm{M})$ correlated with the number of ortho-chlorine substituents; non-ortho-chloro (planar) PCBs were non-toxic. The toxicity to NCC partially correlated with gap junction inhibition, while it fully correlated $(p<0.0004)$ with connexin 43 cellular re-distribution. Thus, our double-SAR strategy revealed a mechanistic step tightly linked to NCC toxicity of PCBs. Connexin43 patterns in NCC may be explored as a new endpoint relevant to developmental toxicity screening.
\end{abstract}

Keywords Cell migration $\cdot$ Cell tracking $\cdot$ Cytotoxicity $\cdot$ High-content imaging $\cdot$ Developmental toxicity $\cdot$ Human stem cells

\section{Abbreviations}

AhR Aryl hydrocarbon receptor

AP1 Activator protein 1

AR Androgen receptor

Electronic supplementary material The online version of this article (https://doi.org/10.1007/s00204-017-2125-4) contains supplementary material, which is available to authorized users.

Marcel Leist

marcel.leist@uni-konstanz.de

1 In vitro Toxicology and Biomedicine, Department Inaugurated by the Doerenkamp-Zbinden Foundation, University of Konstanz, Universitaetsstr. 10, 78457 Konstanz, Germany

2 Research Training Group RTG1331, 78457 Konstanz, Germany

3 Konstanz Research School Chemical Biology (KoRS-CB), 78457 Konstanz, Germany
CAR Constitutive androstane receptor

cMINC Circular MINC

Cx43 Connexin43

Cx43pq Connexin43 plaques

CytoD Cytochalasin D

DMSO Dimethyl sulfoxide

EC Effective concentration

4 Biotechnology Institute Thurgau at the University of Konstanz, 8280 Kreuzlingen, Switzerland

5 Cyprotex Discovery, No 24 Mereside, Alderley Park, Cheshire SK10 4TG, UK

6 BioDetection Systems bv, Science Park 406, 1098XH Amsterdam, The Netherlands

7 Luxembourg Centre for Systems Biomedicine (LCSB), University of Luxembourg, 4362 Esch-sur-Alzette, Luxembourg 


$\begin{array}{ll}\text { EGF } & \text { Epidermal growth factor } \\ \text { ER } & \text { Estrogen receptor } \\ \text { FBS } & \text { Fetal bovine serum } \\ \text { FGF } & \text { Fibroblast growth factor } \\ \text { GJ } & \text { Gap junction } \\ \text { GJIC } & \text { Gap junction intercellular communication } \\ \text { hESC } & \text { Human embryonic stem cell } \\ \text { KE } & \text { Key event } \\ \text { logP } & \text { Hydrophobicity (octanol-water distribution } \\ & \text { coefficient) } \\ \text { MIE } & \text { Molecular initiation event } \\ \text { MTBE } & \text { Methyl-, tert-butyl-ether } \\ \text { MW } & \text { Molecular weight } \\ \text { NCC } & \text { Neural crest cell } \\ \text { PBLs } & \text { Peripheral blood-derived lymphocytes } \\ \text { PBS } & \text { Phosphate buffered saline } \\ \text { PCB } & \text { Polychlorinated biphenyl } \\ \text { PR } & \text { Progesterone receptor } \\ \text { PXR } & \text { Pregnane X receptor } \\ \text { RA } & \text { Retinoic acid } \\ \text { RyR } & \text { Ryanodine receptor } \\ \text { SAR } & \text { Structure-activity relationship } \\ \text { THR } & \text { Thyroid hormone receptor } \\ \text { VDR } & \text { Vitamin D receptor } \\ & \end{array}$

\section{Introduction}

Polychlorinated biphenyls (PCB) are environmental contaminants and are developmentally neurotoxic. Prenatal exposure to PCBs has been associated with poorer short-term memory and verbal comprehension as well as a lower IQ (Jacobson and Jacobson 1996; Jacobson et al. 1990). Mechanisms of PCB neurotoxicity are not fully understood, but effects on neurotransmitters, hormonal balance and intracellular signaling are discussed (reviewed in Kodavanti 2005; Westerink 2014).

We previously reported that PCBs are toxic to a particular fetal cell type, the neural crest cell (NCC). Such NCC arises during early neurodevelopment at the border of the neural plate. After delamination, they migrate to their target site in the body and give rise to a variety of neural and non-neural cell types. By screening diverse environmental contaminants, we found that also several PCBs were among the chemicals that disturb NCC migration at non-cytotoxic concentrations (Dreser et al. 2015; Nyffeler et al. 2017b; Zimmer et al. 2014). However, at present it is unclear which PCB congeners excert this toxicity and by which mechanism migration-inhibition occurs.

The structure of PCBs consists of a biphenyl skeleton with 1-10 chlorine substitutions, leading to 209 different PCB congeners. They have low electrical, but high thermal conductivity. Therefore, PCBs have been used as dielectric and heat transfer fluids in electrical equipment. They are environmentally stable and due to their high lipophilicity tend to accumulate along the food chain (Henry and DeVito 2003; World Health Organization 2000).

Although they share important structural features, PCB congeners differ largely in basic toxicokinetic and physicochemical properties like lipophilicity and volatility. In general, higher chlorinated congeners are less absorbed, but also less readily metabolized and excreted, which leads to their accumulation, particularly in tissues with high lipid contents (Henry and DeVito 2003; World Health Organization 2000).

Moreover, they have different affinities for several cellular receptors. For example, non-ortho chlorinated PCBs tend to be planar, and they share structural similarity with dioxins. Hence, several of them can activate the dioxin receptor (aryl hydrocarbon receptor, AhR) (Safe 1994). Conversely, orthochlorinated, non-planar PCBs have various other cellular targets, such as ryanodine receptors (RyR) and several nuclear receptors (Al-Salman and Plant 2012; Fritsch and Pessah 2013; Hamers et al. 2011; Pessah et al. 2006; Tabb et al. 2004). In addition, other cellular functions have been shown to be impaired by PCBs, for example, dopamine uptake and binding of dopamine to its receptor (Mariussen et al. 2001; Wigestrand et al. 2013).

Several groups have reported that PCBs inhibit gap junction intercellular communication (GJIC) and dislocalize the corresponding proteins in several cell types (Bager et al. 1994, 1997a, b; Brevini et al. 2004; Hamers et al. 2011; Hemming et al. 1991; Kang et al. 1996; Kato et al. 1998; Machala et al. 2003; Simeckova et al. 2009). Gap junctions (GJ) are intercellular channels consisting of conniving oligomers. Each cell forms a connexon consisting of six connexin proteins. Upon connection of two connexons from two neighboring cells, a GJ is formed and small molecules up to $1.2 \mathrm{kDa}$ can be exchanged (Schalper et al. 2014).

Most cells express several connexins, and the connexin pattern differs profoundly among cell types. These proteins seem to be particularly important in developmental processes, such as neuronal migration (Cina et al. 2009; Elias et al. 2007; Fushiki et al. 2003; Wiencken-Barger et al. 2007). In addition, NCC express high levels of connexin 43 (Cx43, GJA1) and display it on the cell surface (Boot et al. 2006; Huang et al. 1998; Li et al. 2007; Ruangvoravat and Lo 1992). Knock-down or knock-out of Cx43 reduces NCC migration (Huang et al. 1998; Xu et al. 2006). The deficiency of $\mathrm{Cx} 43$ can lead to conotruncal heart malformations and delayed development of craniofacial osteoblasts. In both cases, NCC dysfunction plays a role, as the underlying developmental processes heavily rely on NCC (Huang et al. 1998; Lecanda et al. 2000). Knowing this, it is surprising that most studies so far have not found a connection between NCC migration and GJ functioning. It has been argued that 
GJ-independent functions of connexins are essential for NCC (Francis et al. 2011; Xu et al. 2001, 2006).

Although the connection of PCBs and GJ is well established, and the role of GJ in migration is well-known, the effects of PCBs on normal cell migration (different from tumor invasion) have not been considered. In the present study, we investigate the mechanism of PCB-induced migration-inhibition of NCC, as example of a non-transformed cell type. We applied here considerations of the adverse outcome pathway (AOP) concept (Leist et al. 2017) to identify a molecular initiation event (MIE) or a key event (KE) of toxicity. We asked whether the approach of multiple structureactivity-relationship (SAR) comparisons would be a new general approach in modern toxicology to identify MIE/KE of AOP. As PCBs have many cellular targets, it is difficult to find the MIE that leads to migration-inhibition. To help finding the mechanism, we made use of SAR considerations. For this purpose, a set of chemically variable PCBs were tested for their effects on NCC migration. We then overlayed the resulting SAR to existing SARs to reduce the number of possible targets. We identified GJIC as a potential cellular target, and we subsequently showed that PCBs disturbing NCC migration also interfere with $\mathrm{Cx} 43$ localization.

\section{Materials and methods}

\section{NCC differentiation}

NCC were differentiated from H9 (WA09; WiCell, Wiscon$\mathrm{sin}$ ) human embryonic stem cells (hESC) modified to express GFP under the control of the Dll1 promotor (H9-Dll1; provided by M. Tomishima, Memorial Sloan Kettering Cancer Centre, New York, NY, USA) as described earlier (Zimmer et al. 2012). Import of the hESC and all experiments utilizing them were carried out according to German legislation and under the license of the Robert-Koch Institute (license number 1710-79-1-4-27).

Differentiation to NCC was performed exactly as described earlier (Nyffeler et al. 2017b; Zimmer et al. 2012). Briefly, the protocol involves differentiation of hESC to rosettes, manual picking of rosettes and FACSsorting for positive expression of the NCC marker HNK-1 and negative expression of Dll1. The sorted cells were expanded in N2-S medium, consisting of DMEM/F12 (Gibco) and supplemented with $100 \mu \mathrm{g} / \mathrm{ml}$ apotransferrin, $25 \mu \mathrm{g} / \mathrm{ml}$ insulin, $8.6 \mathrm{mM}$ glucose, $100 \mu \mathrm{M}$ putrescine, $30 \mathrm{nM}$ selenite, $20 \mathrm{nM}$ progesterone (all purchased from Sigma-Aldrich), 1× GlutaMax and 1\% penicillin/streptomycin (both from Gibco), $20 \mathrm{ng} / \mathrm{ml}$ epidermal growth factor (EGF) and $20 \mathrm{ng} / \mathrm{ml}$ fibroblast growth factor (FGF) 2 (both from R\&D). After 27-30 days, cells were cryopreserved until further use. For all experiments, freshly thawed NCC were used and cultured on poly-L-ornithine/ fibronectin/laminin coated plates in N2-S medium supplemented with $20 \mathrm{ng} / \mathrm{ml} \mathrm{EGF}$ and $20 \mathrm{ng} / \mathrm{ml} \mathrm{FGF2}$.

\section{NCC migration assay ('cMINC')}

The NCC migration assay was performed exactly as described in Nyffeler et al. (2017b). Briefly, cells were seeded $\left(95,000\right.$ cells $\left./ \mathrm{cm}^{2}\right)$ in poly-L-ornithine/fibronectin/ laminin coated 96-well plates containing silicon stoppers (Platypus Technologies, Madison, WI, US) to create a circular cell-free area. One day after seeding, stoppers were removed to initiate migration and medium was refreshed. After $24 \mathrm{~h}$, test compounds were added (in general as $5 \times$ concentrate relative to the final test concentration), and after additional $24 \mathrm{~h}$ of incubation, migration and viability was measured. For each biological replicate, four technical replicates were performed. For testing of protecting inhibitors, inhibitors were added as $10 \times$ concentrate relative to the final test concentration for $1 \mathrm{~h}$, before PCBs were added as $10 \times$ concentrate for $24 \mathrm{~h}$. A list of the tested PCBs and inhibitors is given in the Supporting Information.

Image acquisition was performed exactly as described in Nyffeler et al. (2017b) by staining with H-33342 and calcein-AM and imaging with a high-content imaging microscope (Cellomics ArrayScanVTI, Thermo Fischer). Viability was defined as the number of H-33342 and calcein double-positive cells, as determined by an automated algorithm described earlier (Krug et al. 2013; Stiegler et al. 2011). For quantification of migration, a software tool (freely accessible at http://invitrotox.uni-konstanz.de/) was developed to estimate the most likely position of the previously cell-free area (covered by the silicon stopper), to set thresholds for color intensity for both dyes, and to count the number of H-33342 and calcein double-positive cells in the region of interest. If not mentioned otherwise, viability and migration were normalized to untreated or solvent control (0.1\% DMSO). In a typical experiment, 2000-2500 viable cells were counted for the control and 150-300 migrated cells were in the region of interest. Concentration-response curves from averaged data $(n=3$ experiments) were fitted using R (R Core Team 2015) and the package 'drc' (Ritz and Streibig 2005) to a log-logistic function with four parameters as described in Nyffeler et al. (2017a). Effective concentration (EC) values of the fitted curves were estimated (EC90 of viability and EC50 of migration) and the amount of migration at the EC90 of viability was estimated. If the EC90 of viability was above the highest tested concentration, the extent of migration at the highest tested concentration was used instead. 


\section{Time-lapse experiment and cell tracking}

Cells were seeded under standard cMINC conditions and imaged during the 24-h treatment period as described in Nyffeler et al. (2017a). Live cell imaging was performed using an Axio Observer.Z1 microscope (Zeiss, Oberkochen, Germany) equipped with an Axiocam MRm camera and an incubation system $\left(37{ }^{\circ} \mathrm{C}, 5 \% \mathrm{CO}_{2}\right)$. Phase contrast images of the migration zone were acquired every 10 min using a $5 \times$ objective. After the time-lapse, migration and viability were determined as described in the 'NCC migration assay' section to ensure that the toxicants worked as under standard cMINC conditions with exposure in a standard incubator. Cells were manually tracked using the ImageJ plugin 'Manual Tracking' in reverse time. Cells were selected for tracking if they were; (1) viable (i.e., not rounded up) at the end of the time-lapse, (2) located in the circular migration zone at the end of the time-lapse and (3) trackable for the entire time-lapse (i.e., did not leave the imaging frame). For each biological replicate, ten individual cells were tracked per condition (and 20-30 cells for the untreated control). The cumulated distance of each cell was normalized to the median of the untreated control population. Statistical significance of differences between treated and non-treated conditions was calculated on the combined data of two biological replicates using a two-sided Wilcoxon rank sum test.

\section{Transwell migration assay}

The transwell inserts (pore size $8 \mu \mathrm{m}$, polycarbonate membrane, Corning, catalog no. 3422) were pre-coated with poly-L-ornithine/fibronectin/laminin. Cells $(100 \mu \mathrm{l})$ were seeded at a density of 50,000 cells per insert $(150,000$ cells/ $\mathrm{cm}^{2}$ ) into the upper chamber. After $1 \mathrm{~h}$, test compounds were added as $5 \times$ concentrate $(25 \mu \mathrm{l})$ to the upper chamber and $600 \mu \mathrm{l}$ as $1 \times$ concentrate to the lower chamber. After $3 \mathrm{~h}$, cells were stimulated to migrate through the membrane by addition of fetal bovine serum (FBS) to the lower chamber (final conc. 5\%). The cells were incubated for $6 \mathrm{~h}$ at $37^{\circ} \mathrm{C}$ and $5 \% \mathrm{CO}_{2}$ and allowed to migrate. After incubation, the medium was aspirated from inserts and reservoirs and then the upper side of each insert was gently swabbed, using cotton swabs, to remove cells that had not migrated through the membrane. Reservoirs and inserts were washed once with phosphate buffered saline (PBS) and then the migrated cells were fixed with $3.7 \%$ formaldehyde and stained with crystal violet for $10 \mathrm{~min}$. Then, the inserts were thoroughly rinsed with water and dried for at least $24 \mathrm{~h}$. To evaluate the number of migrated cells through the membrane, five pictures per condition were taken under the light microscope. In a typical experiment, stimulation with FBS led to ca. 100 migrated cells per picture. The number of migrated cells for all data displays was normalized to that of cells stimulated only with FBS in the absence of toxicants. Data are from $\geq 3$ independent experiments. In each experiment, there were two technical replicates (transwell inserts) for the control and one for treatment condition. Data for each technical replicate are based on five imaging fields.

\section{Assessment of migration in various cell types}

The human breast adenocarcinoma cell line MDA-MB-231 and the murine fibroblast cell line NIH-3T3 were maintained in DMEM with $4.5 \mathrm{~g} / \mathrm{l}$ glucose and Glutamax (Gibco) supplemented with $10 \%$ FBS and $1 \%$ penicillin/streptomycin. For assessment of migration, cells were seeded $(63,000$ cells $/ \mathrm{cm}^{2}$ ) into 96-well plates containing silicon stoppers. One day after seeding, stoppers were removed to initiate migration, and medium was refreshed. Toxicants were added as $5 \times$ concentrate (in $20 \%$ of the final culture volume), and cells were allowed to migrate for $24 \mathrm{~h}$ before migration and viability were assessed as described in 'NCC migration assay'. Cytochalasin D (CytoD), an actin polymerization inhibitor, was used as a positive control to ensure that the conditions allowed to measure inhibition of migration. Two biological experiments were performed with four technical replicates each.

For assessment of PCB cytotoxicity on peripheral bloodderived lymphocytes (PBL), blood donation for research purposes was approved by the local institutional review board, and individual donors gave written consent. Peripheral blood mononuclear cells from healthy donors were enriched by density gradient centrifugation on Ficoll-Paque Plus (Amersham Biosciences). Monocytes were depleted from the cell pool with anti-CD14-conjugated microbeads (Miltenyi). The remaining PBLs were cultured in RPMI1640 medium supplemented with $2 \%$ human $A B$ serum, $1 \%$ non-essential amino-acids and $0.5 \% \beta$-mercaptoethanol (Lonza). They were treated with PCBs or vehicle control (DMSO) for 16-20 h. Cells were harvested and stained with TO-PRO ${ }^{\circledR}{ }^{\circledR}-3$ (ThermoFischer Scientific) to distinguish live from dead cells and quality controlled on an LSRII flow cytometer (BD Biosciences). Chemotaxis of PBL treated with PCBs or vehicle control (DMSO) for 16-20 h was quantified by measurement of migration through a polycarbonate filter of $5 \mu \mathrm{m}$ pore size in 24-well Transwell ${ }^{\mathrm{TM}}$ chambers (Corning Costar) as previously described (Hauser et al. 2016). Cell culture medium $(600 \mu \mathrm{l})$ containing $500 \mathrm{ng} /$ $\mathrm{ml}$ of the chemokine CCL21, or medium alone as a control for spontaneous migration, was added to the lower chamber; $10^{6}$ cells in $100 \mu \mathrm{l}$ were added to the upper chamber. After 1-h incubation at $37{ }^{\circ} \mathrm{C}$, a $500 \mu \mathrm{l}$ aliquot of the cells that migrated to the bottom chamber was counted by flow cytometry by acquiring events for a fixed time of $60 \mathrm{~s}$ using the Diva software. Specific cell migration was calculated by subtracting the number of cells migrating in the absence of 
chemokines. The number of specifically migrated cells was expressed as percent of input cells and compared to the vehicle control. Viability data are from one biological experiment, whereas chemotaxis experiments were performed with PBLs from three different blood donors.

\section{Quantification of PCB distribution in the well}

Three types of samples were produced: (I) PCB $(5 \mu \mathrm{M})$ in cell culture medium in low-absorbance vessels; (II) solution I in a standard coated cell culture dish; (III) solution I in a coated cell culture dish containing cells. PCB content was measured from conditions II and III after 3 or $24 \mathrm{~h}$. For condition III, cells were cultured exactly as described under 'NCC migration assay' with the exception that no silicon stoppers were introduced. Cells were treated 2 days after seeding with solution I.

PCBs were extracted from the samples by extraction with methyl-, tert-butyl-ether (MTBE). From each sample, $40 \mu \mathrm{l}$ were transferred into a fresh vial and an equal volume of water containing $0.1 \%$ formic acid (Fisher Scientific) was added. The sample was transferred to a supported liquid extraction plate. A positive pressure was applied to load the sample into the plate. MTBE (Fisher Scientific) was added to each well and left to pass through the plate and into a glass insert. The collected sample was dried under nitrogen at $30^{\circ} \mathrm{C}$. Each sample was reconstituted in a volume of MTBE and capped for injection into the gas chromatography-mass spectrometer along with an internal standard (phenanthrene, Sigma-Aldrich). Further analytical details are given in the Supporting Information. To quantify the PCB amount, a serial dilution of solution I was quantified to obtain a calibration curve. PCB content of wells with and without cells was normalized to this calibration sample (considered as $100 \%)$. The PCB amount bound to plastic was calculated from the difference I-II. Intracellular PCB amounts were calculated from the difference I-II-III. The experiment was performed three times.

\section{CALUX bioassays for nuclear receptors and stress pathways}

The panel of tested cell lines contained the DR CALUX (Garrison et al. 1996), which is a rat H4IIE liver cell based cell line expressing the dioxin receptor (AhR) endogenously. The other selected cell lines are the ER $\alpha$ CALUX and AR CALUX (Sonneveld et al. 2005), and the PR CALUX and PXR CALUX (van der Burg et al. 2015, van der Burg in preparation), all of which are human U2-OS cell lines stably transfected with an expression construct for the human estrogen (ER), androgen (AR), progesterone (PR) or pregnane X (PXR) receptor, and a reporter construct consisting of multimerized responsive elements for the cognate receptor coupled to a minimal promoter element (TATA) and a luciferase gene. The panel was completed with two U2-OS-based singly transfected lines expressing a reporter gene only, designed to selectively measure the activity of the endoplasmic reticulum stress pathway (ESRE CALUX) and the activator protein 1 pathway (AP1 CALUX), respectively (van der Burg et al. 2013). The Cytotox CALUX, used as a control line for non-specific effects, consisted of human U2-OS cells stably transfected with an expression construct constitutively expressing the luciferase gene, and is described in van der Linden et al. (2014).

Cells were maintained as described previously (Sonneveld et al. 2005). The automated CALUX assays were carried out as described earlier (van der Burg et al. 2015). In brief, the assay was performed in assay medium, consisting of DMEM without phenol red indicator (Gibco) supplemented with 5\% DCC-stripped FBS, $1 \times$ non-essential amino acids (Gibco) and $10 \mathrm{U} / \mathrm{ml}$ penicillin and $10 \mu \mathrm{g} /$ $\mathrm{ml}$ streptomycin. A cell suspension in assay medium was made of $1 \times 10^{5}$ cells $/ \mathrm{ml}$, and white 384-wells plates were seeded with $30 \mu \mathrm{l}$ cell suspension/well. After $24 \mathrm{~h}$, exposure medium was prepared. A dilution series in $0.5 \log$ unit increments of each test compound (in DMSO) was added to a 96-well plate containing assay medium. Of this exposure mixture, $30 \mu \mathrm{l}$ was added to the assay plates containing the CALUX cells. Additionally, DMSO blanks and a full concentration response curve of reference compounds were included on each plate. The final solvent concentration in the well was $1 \%$. All samples were tested in triplicates. The preparation of the compound dilution series as well as the exposure of the cells were performed on a Hamilton Starlet liquid handling robot coupled to a Cytomat incubator. To be able to detect receptor antagonism, the AR- and PR CALUX assays were performed in antagonistic mode. The assay procedure was as described above, with the only exception that the EC50 concentration of the reference agonist was present during the exposure.

After $24 \mathrm{~h}$ exposure the exposure medium was removed using an EL406 washer-dispenser (BioTek) and $10 \mu \mathrm{l} /$ well triton lysis buffer was added by the EL406. Subsequently, the luciferase signal was measured in a luminometer (InfinitePro coupled to a Connect Stacker, both TECAN).

The luminometer data was analyzed as following: the average of the triplicate wells was determined, and the average blank (DMSO) value was subtracted. The maximum response elicited by the reference compound was set to $100 \%$ (full receptor- or pathway activation), and the other values were scaled accordingly. Graph Pad Prism was used to fit a sigmoidal curve through the data (four parameters, variable slope). The EC10 concentration was defined as the concentration where the response elicited by the test compound equals $10 \%$ of the maximum response of the reference compound. For antagonist experiments, EC20 values were 
determined instead, which were defined as the concentration where the test compound causes $20 \%$ inhibition of the basal signal elicited by the receptor agonist which was set to $100 \%$.

\section{Literature research}

The literature was searched for structure-activity-relationship studies of PCBs with various cellular targets and key events (KE). Results of PCBs with 4 to 8 chlorine substitutions (e.g., PCB40-PCB205) were considered. Tested PCBs were categorized as active/inactive based on the conclusions in the respective publications. For two publications, we developed our own categorization scheme: for CYP1A1 induction and PXR activation in Al-Salman and Plant (2012), PCBs were considered active if they led to $>$ twofold induction. For human PXR activation in Tabb et al. (2004), PCBs were considered active if the readout was significantly increased (at the $5 \%$ level) or if the fold change was $>5$. For PXR antagonism in the same study, PCBs were considered active if $\mathrm{Ki}$ was $<9 \mu \mathrm{M}$.

\section{Parachute assay to measure gap junctional communication}

Cells were seeded $\left(95,000\right.$ cells $\left./ \mathrm{cm}^{2}\right)$ in PLO/fibronectin/ laminin coated 24-well plates and cultured under standard cMINC conditions with $600 \mu \mathrm{l}$ medium/well. After 2 days in culture, treatment was initiated. Four hours before quantification of the assay endpoint, donor cells were labeled. For this, cells kept in parallel under control conditions were stained for $30 \mathrm{~min}$ with calcein-AM (533 nM final conc.; Sigma). After two washing steps with pre-warmed PBS, $150 \mu \mathrm{l}$ HyClone HyQTase (GE Healthcare Life Sciences) was added for $20-30 \mathrm{~min}$ at $37^{\circ} \mathrm{C}$ to detach the cells. Then, cells were washed [medium $(450 \mu \mathrm{l})$ was added, cells were centrifuged and supernatants were removed], followed by resuspension in $600 \mu \mathrm{l}$ of fresh medium. An aliquot $(6 \mu \mathrm{l}+54 \mu \mathrm{l}$ fresh medium) of this donor population was added to each well with acceptor cells (i.e., various treatment conditions). Under these conditions, the donor:acceptor ratio was about 1:100. Dye-transfer was allowed to occur for a total of $3 \mathrm{~h}$. During the last $30 \mathrm{~min}, 1 \mu \mathrm{g} / \mathrm{ml} \mathrm{H}-33342$ was added, to label cell nuclei. Imaging was performed on a high-content imaging microscope (Cellomics ArrayScanVTI, Thermo Fischer) equipped with a Hamamatsu ORCAER camera of $1024 \times 1024$ pixel resolution run at $2 \times 2$ binning mode. Of each well, 49 fields were imaged using a $5 \times$ lens.

The obtained images were exported to TIF format and analyzed using R (R Core Team 2015) and the package 'EBImage' (Pau et al. 2010). In a first step, the calcein image was normalized, background and gamma corrected.
Donor and acceptor cells were defined based on pixel brightness. A watershed algorithm defined the regions with (parachuted) donor cells and their acceptor area as objects. Objects with donor cells $<60$ or $>500$ px or with an acceptor area $>3000 \mathrm{px}$ or too low nuclei density (based on the H-33342 channel) were excluded. From the remaining valid objects, the ratio of the area (in px) of acceptor cells and the corresponding donor cell was calculated and compared between treatments. To this end, the values of all untreated controls (usually three wells with 49 pictures each) were pooled and the median calculated. For each treatment well, the percentage of ratios greater than the median of the untreated control was calculated and normalized to the untreated control. Data displayed are from three biological experiments with $>100$ valid objects per experiment.

\section{Immunofluorescence staining}

For immunocytochemical staining, cells were fixed for 20 min by adding one volume of $4 \%$ formaldehyde and $2 \%$ sucrose in phosphate buffered saline (PBS) to the medium. For intracellular epitopes, cells were permeabilized for 15 min with $0.1 \%$ Triton, followed by blocking with $10 \%$ FBS in PBS for $1 \mathrm{~h}$ before primary antibodies were applied in 10\% FBS in PBS overnight. The next day, cells were washed with $0.05 \%$ Tween in PBS and secondary antibodies were applied for $1 \mathrm{~h}$. Cell nuclei were counterstained with $1 \mu \mathrm{g} / \mathrm{ml} \mathrm{H}-33342$ for $10 \mathrm{~min}$. Images were acquired using a laser scanning confocal microscope (Zeiss LSM 700, Zeiss, Oberkochen, Germany) or an Axio Observer.Z1 microscope (Zeiss, Oberkochen, Germany). The list of antibodies and their dilutions can be found in the Supporting Information.

\section{Quantification of connexin43 plaques (Cx43pq)}

Cells were seeded $\left(95,000\right.$ cells $/ \mathrm{cm}^{2}, 315 \mu \mathrm{l}$ medium/well) in PLO/fibronectin/laminin coated 8-well $\mu$-slides with glass bottom (iBidi, Munich, Germany). After 1 day, medium was refreshed $(320 \mu \mathrm{l})$. After another day, test compounds were added ( $80 \mu \mathrm{l}, 5 \times$ concentrate; for $0.5-3 \mathrm{~h}$ ) before cells were fixed and stained for $\mathrm{Cx} 43$ as described in 'Immunofluorescence staining'. Images were acquired manually on an Axio Observer.Z1 microscope (Zeiss, Oberkochen, Germany) equipped with an Axiocam MRm camera and appropriate filters using the $20 \times$ lens by focusing on the connexin 43 plaques (Cx43pq) and imaging H-33342 with an offset of $-8 \mu \mathrm{m}$. Exposure time for connexin 43 was chosen in a way that the plaques were overexposed, but not other cellular structures. Images were exported to TIF format and analyzed using R (R Core Team 2015) and the package 'EBImage' (Pau et al. 2010). Images were thresholded to display only pixels with an intensity $>0.8$ (on a normalized scale of $0-1$ ), followed by segmentation of the remaining objects. Objects 
with an area $<10$ pixels (px) were counted as connexin43 plaques $(\mathrm{Cx} 43 \mathrm{pq})$. A typical image of a solvent control culture $(512 \times 512 \mathrm{px}$; i.e., about $400 \mu \mathrm{m}$ wide) contained approximately 50 such objects. For each condition, 10-15 images were analyzed, averaged, and normalized to the solvent control. Data displayed are from at least two independent biological experiments.

\section{Data handling and statistics}

If not mentioned otherwise, values are expressed as means \pm SD from three independent experiments. Independent experiments are here also called 'biological replicates' (Aschner et al. 2017; Leist et al. 2010) and they are defined as using different cell preparations (while technical replicates here correspond to different cell culture wells within one experiment). The statistical methods (parametric and non-parametric) were adapted to the questions behind the experiment and are specified in the figure legends. Calculations were done in Excel and R, for data display GraphPad Prism and $\mathrm{R}$ were used.

\section{Results}

\section{Differential effects of PCBs on NCC migration}

Previous studies had shown that some di-ortho chlorinated PCBs can inhibit NCC migration (Dreser et al. 2015; Nyffeler et al. 2017b). Here we asked whether this was a general feature of PCBs. For this purpose, we chose a di-ortho PCB (PCB180), a mono-ortho (PCB118) and a non-ortho (PCB77) chlorinated congener (Fig. 1a), and they were tested in three different migration assays.

The first test was a transwell migration assay. Under control condition, NCC migrates towards a chemoattractant stimulus (serum) within $6 \mathrm{~h}$. Upon pre-treatment with PCB118 and PCB180, transwell migration was drastically reduced in a concentration-dependent manner, while PCB77 did not inhibit transwell migration in a similar concentration range (Fig. 1a). These data suggest that PCBs have differential effects on NCC migration. To confirm the findings by direct observation, the migration speed of single cells was determined by a method as described earlier (Nyffeler et al. 2017a, b). For this purpose, cells were seeded in 96-well plates containing silicon stoppers that create a circular cell-free area. Upon removal of the stoppers, NCC started to migrate into the cell-free area (Fig. 1b). PCB118 and PCB 180 decreased the traveled distance of single cells (e.g., the average cell speed in $24 \mathrm{~h}$ ) by approx. $50 \%$ (Fig. 1c). These experiments also showed that the PCB exposure slowed down the cells already after few hours (data not shown), while the non-ortho chlorinated PCB77 did not affect cell speed at any time. Analysis of NCC migration using high-content imaging, and quantification of the number of migrated cells (Nyffeler et al. 2017a, b) confirmed these findings. While PCB77 did not affect migration at concentrations up to $40 \mu \mathrm{M}, \mathrm{PCB} 118$ and PCB 180 inhibited migration at low micromolar concentrations and in a concentration-dependent manner that did not affect the number of viable cells (Fig. 1d). Altogether, these results indicated that not all PCB congeners interfere with NCC migration.

\section{Negligible effects of PCBs on the migration of other cell types}

We wondered why the strong effects of PCBs on cell migration had received little attention earlier. Therefore, we investigated whether other migratory cell types would also be affected in a similar way as NCC. For this purpose, a human breast cancer cell line (MDA-MB-231), and mouse embryonic fibroblasts (NIH-3T3) were chosen as well-established models for cell migration. A modified version of the cMINC high-content imaging setup was used to quantify cell migration over a $24-\mathrm{h}$ period. Under these conditions, the positive control cytochalasin D strongly inhibited migration, while PCB118 and PCB180 neither affected migration nor viability (although concentrations up to $25 \mu \mathrm{M}$ were tested, Fig. 2a). To follow-up on these negative findings, we chose peripheral blood lymphocytes (PBL) as a primary cell type known to be very motile. The latter cells typically migrate at much higher speed than NCC, and they were therefore tested in a $1 \mathrm{~h}$ transwell setup (using the well-established chemokine CCL21; Hauser and Legler 2016). Cells exposed to PCB180 $(25 \mu \mathrm{M})$ migrated to the same extent as under control conditions, even if they were pre-treated with the toxicant for $20 \mathrm{~h}$ (Fig. 2b).

These results suggest that the migration-inhibitory effect of PCBs is limited to a few cell types. Concerning the effects observed here for NCC, the cell type specificity may be due to the interference of PCBs with a cellular process particularly important for this fetal cell population, but not for general cell migration. Alternatively, PCBs might act by binding to a 'receptor' expressed by NCC, but not by other cell types.

\section{Bioavailability of migration-inhibiting PCBs}

PCBs have been used for mechanistic studies in a broad concentration range. An in vivo single digit micromolarity seems to be feasible (Choi et al. 2003; Jensen 1989; Wassermann et al. 1979), and is considered realistic in recent studies (Pierucci et al. 2017; Ziegler et al. 2017), while concentrations clearly beyond this limit pose experimental problems (solubility) and may not be toxicologically relevant. We observed here that PCB118 and PCB180 strongly inhibited migration at $5 \mu \mathrm{M}$. We were interested in whether 
A<smiles>Oc1ccc(-c2ccc(Cl)c(O)c2)cc1O</smiles>

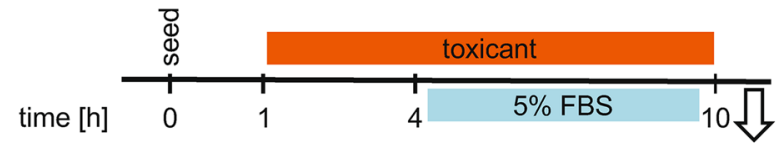

PCB118

non-ortho PCB

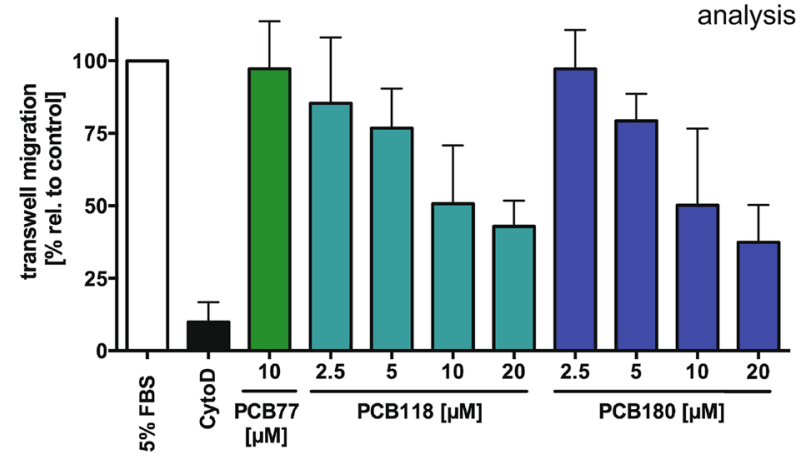

B

PCB180<smiles>Oc1ccc(-c2cc(O)c(O)cc2O)cc1O</smiles>

mono-ortho PCB
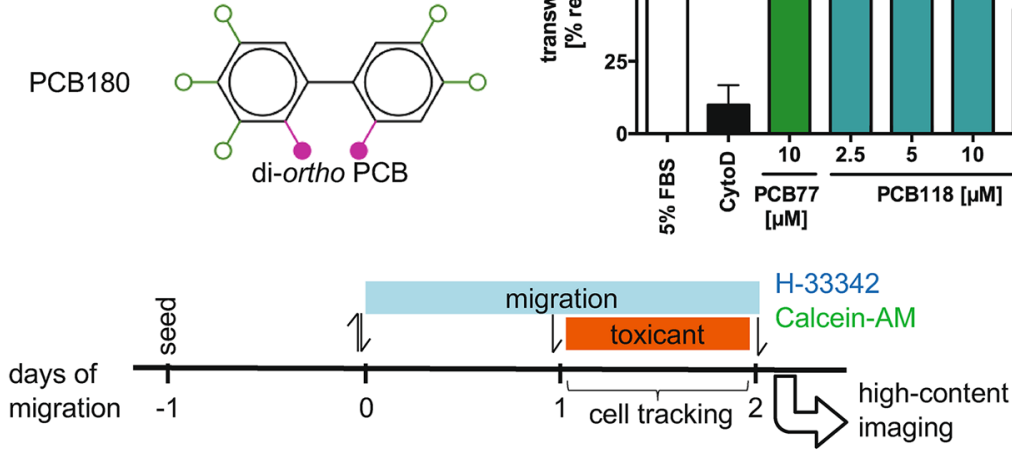

C Migration tracks [24 h]:

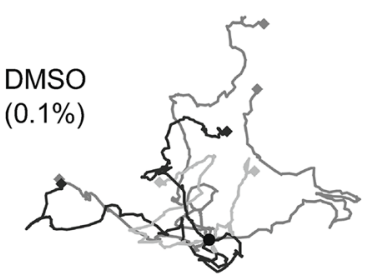

PCB180

$(8 \mu \mathrm{M})$
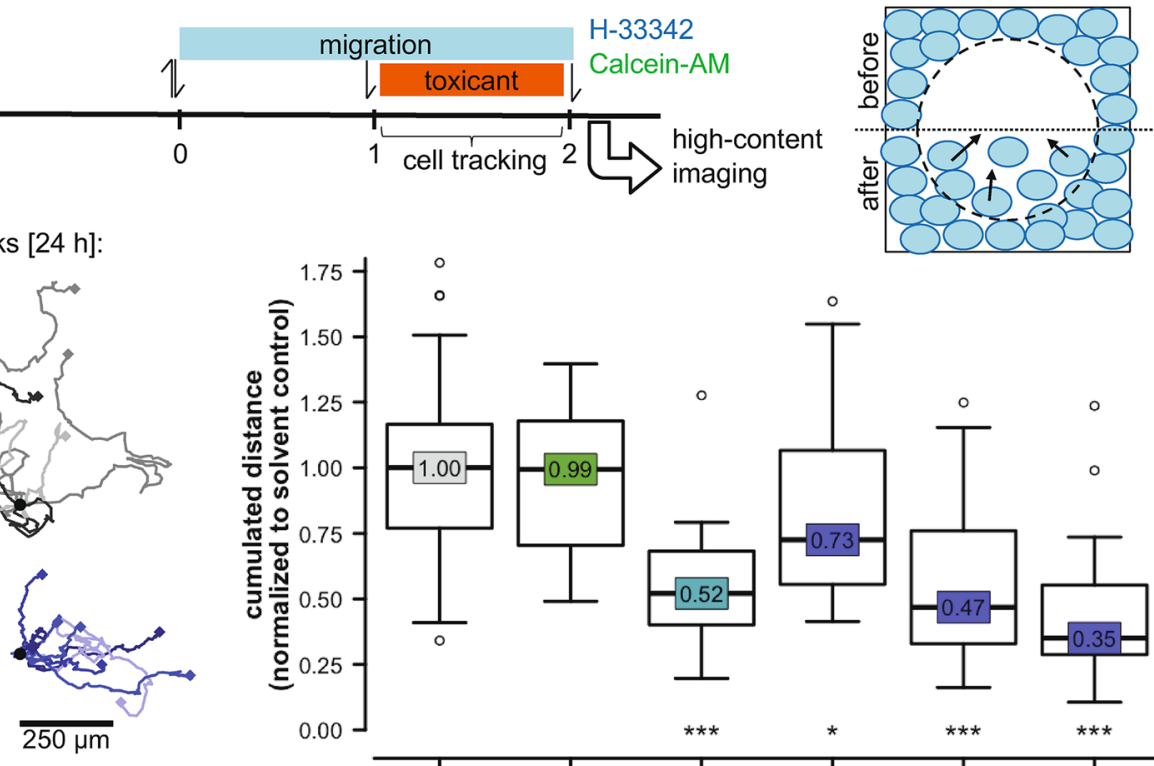

D High-throughput measurement:
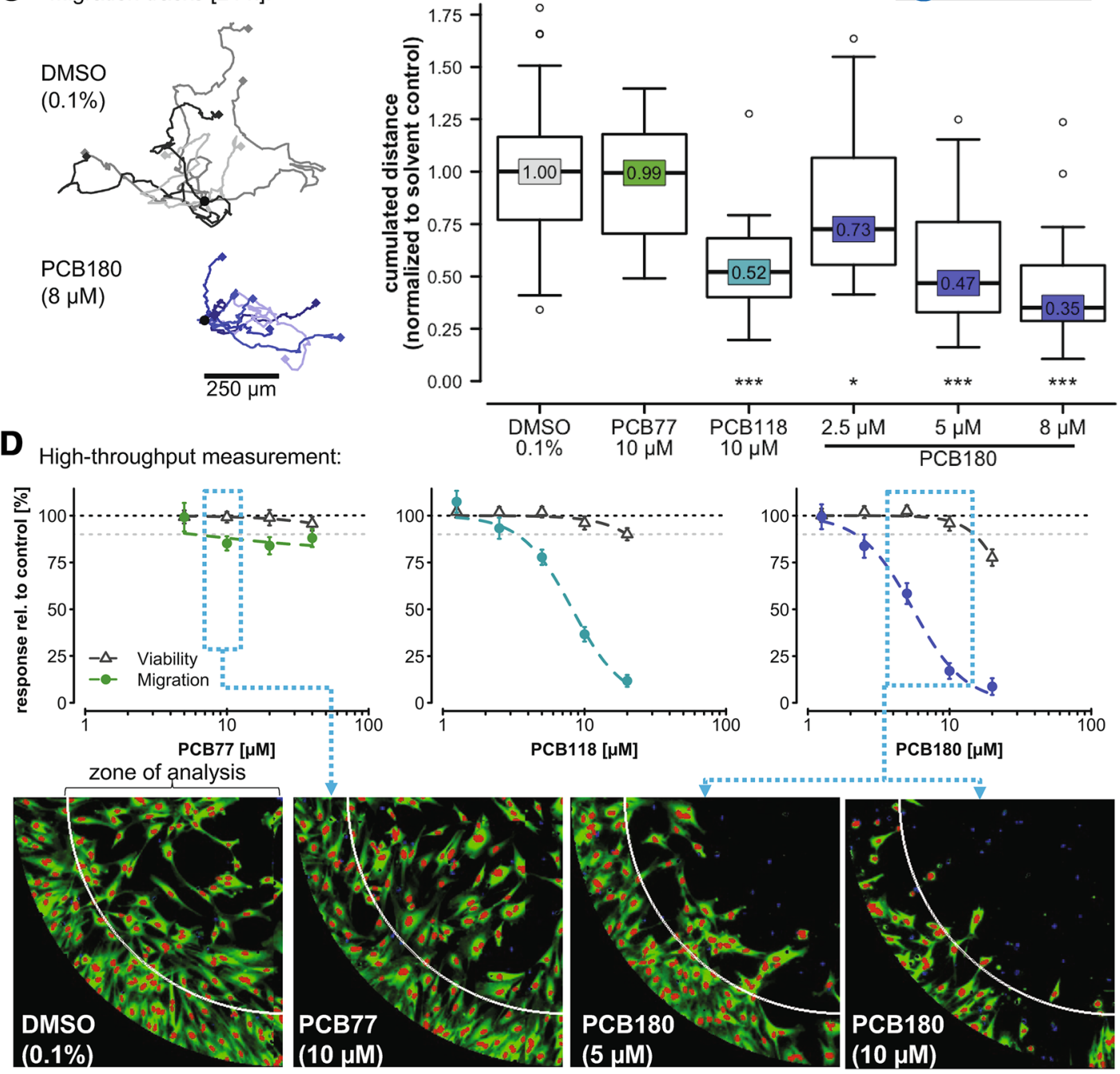
४Fig. 1 Different effects of polychlorinated biphenyls (PCBs) on neural crest cell migration. a The chemical structures of the tested PCBs are illustrated with chlorine residues marked in purple (ortho position) and green (meta and para position). PCBs testing in the classical Boyden-type chemotaxis assay. Cells were seeded into transwell inserts (upper assay compartment) and treated $1 \mathrm{~h}$ later with the toxicant. At $4 \mathrm{~h}$ after plating, cell migration was triggered by addition of $5 \%$ fetal bovine serum (FBS) to the lower compartment. At $10 \mathrm{~h}$ after plating, migrated cells were fixed, stained and counted. Transwell migration under various experimental conditions is expressed as number of migrated cells relative to the control condition (stimulation with 5\% FBS alone). Cytochalasin D (CytoD; $200 \mathrm{nM}$ ) was used as positive control for the test. Data are expressed as means \pm SD from three independent biological experiments. b Graphical representation of the setup for the cMINC assay and cell tracking: cells were seeded in 96-well plates containing silicone stoppers to create a cellfree circular area. After 1 day, stoppers were removed to allow cells to migrate. PCBs were added after 1 day, and left on cells for further $24 \mathrm{~h}$. Time-lapse video microscopy for cell tracking took place during the $24 \mathrm{~h}$ treatment period. For high-content imaging, cells were visualized using H-33342 (nuclear stain) and calcein-AM (viable cells). Cell migration was assessed by counting cell numbers in the central migration zone; cell viability was determined from the same wells using images of the well periphery. The scheme to the right illustrates graphically the assay principle of cell movement into the circular zone during the course of the assay. c Effects of PCBs on individual cell speed. Time-lapse video microscopy was performed during the toxicant exposure and the migration track of individual cells was followed. On the left, representative tracks are visualized for cells treated with $0.1 \%$ DMSO (solvent control) or $8 \mu \mathrm{M}$ PCB180. On the right, data are shown for various PCB treatments. The box represents the first and third quartiles, the black line the median (number given in the rectangle). For each treatment condition, 20 individual cells were tracked and for each cell, the cumulated travelled distance was normalized to the solvent control. Statistical significance of differences between treated and non-treated conditions was calculated using a Wilcoxon rank sum test. Statistical indicators are given below the boxes: ${ }^{*} p<0.05, * * p<0.01, * * * p<0.001$. d Effects of PCBs in the high-throughput cMINC assay. Concentration-response curves of the tested PCBs for viability (gray triangles) and migration (colored circles). All values are normalized to untreated control. The horizontal gray dotted lines indicate the $100 \%$ value and the threshold for cytotoxicity at $90 \%$, respectively. Data are expressed as means \pm SD from three independent biological experiments. Below are representative images of the 'migration zone' (one quarter of the circular zone is shown) after exposure to the tested PCBs. The cell cytoplasm is depicted in green; nuclei of viable cells are depicted in red. The white line indicates the area included for analysis of migration. (Color figure online)

this nominal concentration (Groothuis et al. 2015) roughly corresponded to the total concentration of PCB in cell culture medium. Therefore, the PCB contents in the different compartments of a culture dish (in the cell supernatant, bound to plastic and intracellular) were assessed by chemical analysis. To this end, cells were incubated with $5 \mu \mathrm{M}$ PCB for 3 or $24 \mathrm{~h}$. It became apparent, that after $3 \mathrm{~h}, 25-50 \%$ of PCB bound to the cell culture dish plastic (Fig. 3). This fraction increases to around $75 \%$ after $24 \mathrm{~h}$. This means that the available PCB concentration was $25-75 \%$ of the nominal concentration, i.e., about 1.2-3.8 $\mu \mathrm{M}$, when $5 \mu \mathrm{M}$ were tested. Additionally to PCB118 and PCB180, several non-ortho, mono-ortho, di-ortho and tri-ortho PCBs were tested for their binding to cell culture dishes. After 3-h incubation, about $60 \%$ of PCB (PCB 126, 169, 95, 132, 110, $153,167)$ bound to the cell culture dish plastic. The fraction bound to plastic was similar for all tested PCBs, and therefore the real available PCB concentration in the cell culture medium was about $2 \mu \mathrm{M}$ instead of the nominal concentration of $5 \mu \mathrm{M}$. Some PCB may have accumulated also in the cells. However, this was less than $10 \%$ of the total amount (and associated with a large variance). It could therefore not be exactly quantified. In conclusion, the cells were exposed to extracellular PCB concentrations lower than the nominal concentrations, but still within the same order of magnitude. Since plastic adsorption played an important role, these data suggest that experimental standardization (e.g., consistent conditions, culture ware, etc.) was highly important for our study.

\section{Investigation of important cell functions as potential targets of $P C B s$}

One explanation for apparently specific inhibition of NCC by PCBs could be that these cells are particularly sensitive to PCB toxicity. Although we found that general viability measures were not affected at concentrations that inhibited migration, some more subtle effects may have remained undetected. A cell function that is possibly more important for migration (in the time frame of the cMINC assay) than for overall viability is the correct and efficient production and intracellular transport of proteins (especially to and from the cell membrane). Glycosylation of proteins is a critical function of the biosynthetic-secretory pathway that may be used as functional readout (Arvan et al. 2002; Ferris et al. 2014). Therefore, we investigated whether PCBs affected this cell biological process. For the measurement, we used a well-established method from the field of metabolic glycoengineering (Prescher and Bertozzi 2005): we fed cells with a modified sugar precursor, and subsequently quantified how efficient this chemical biological tool was incorporated as sialic acid into the pool of membrane glycoproteins ( $\mathrm{Du}$ et al. 2009; Kang et al. 2015; Niederwieser et al. 2013). The assay had a large dynamic range for NCC, and use of positive controls (tunicamycin and brefeldin A, known inhibitors of the $\mathrm{N}$-glycosylation pathway) showed a very pronounced inhibition of the assay endpoint, independent of overt cytotoxicity (Fig. S1). None of the tested PCBs (PCB118 and PCB 180) affected the display of the metabolized and incorporated sugar (sialic acid) on the plasma membrane (Fig. S1). Thus, many complex cellular processes, requiring Golgi functioning, protein trafficking and glycoprotein synthesis, seemed to be unaffected by exposure to PCB.

As an additional approach, the cellular status was examined by microscopy and by quantification of gene 


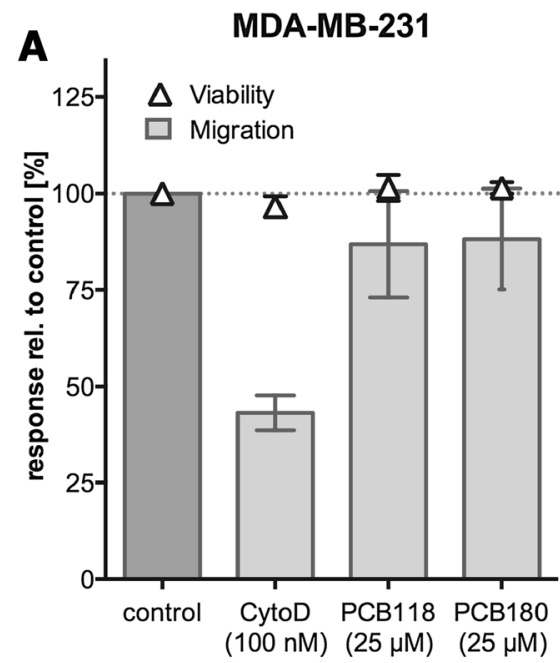

Fig. 2 Effect of PCBs on migration of various other cell types. a MDA-MD-231 (human breast carcinoma) and NIH-3T3 (mouse fibroblast) cells were used in the cMINC format. They were seeded in 96-well plates containing silicone stoppers to create a cell-free circular area. One day after plating, stoppers were removed and cells allowed to migrate in the presence of test compounds for $24 \mathrm{~h}$ (followed by live cell staining with H-33342 and calcein-AM and highthroughput imaging). Cell migration (gray bars) was assessed by counting cell numbers in the central migration zone; cell viability (triangles) was determined from the same wells. All values are normalized to untreated control (exposed only to the solvent DMSO).

expression. Overall cell morphology and cytoskeletal structure remained within the range of normal variations, and the expression of several differentiation markers (e.g., nestin) remained unchanged upon treatment with PCB180 $(10 \mu \mathrm{M})$ (Fig. S2A). Moreover, cadherins and integrins (cell-cell and cell-matrix receptors involved in cell migration), were neither up- nor down-regulated upon PCB180 treatment (Fig. S2B, C).

Next, we investigated whether targets of PCBs known from the literature would qualify as candidates for MIE, i.e., whether they were responsible for the adverse outcome in our test (functional impairment of NCC with regards to migration; Fig. 4a). As PCBs are known to directly interact with the AhR, the RyR, and several nuclear receptors, we tested whether agonists and antagonists of these receptors affected NCC migration. Ligands of the AhR did not show effects in the cMINC assay (Fig. 4b), even though the receptor appeared to be biologically active (target genes were induced by the dioxin-like non-orthochlorinated PCBs 77, 126 and 169; Fig. S3A). RyR also had no effect on migration, and the same was true for thyroid receptor (THR) ligands (Fig. 4b). In a further series of experiments, we investigated whether receptor modulation affected the migration-inhibitory effect of PCB180. Neither AhR, nor RyR or THR modulation blocked the effect
NIH-3T3

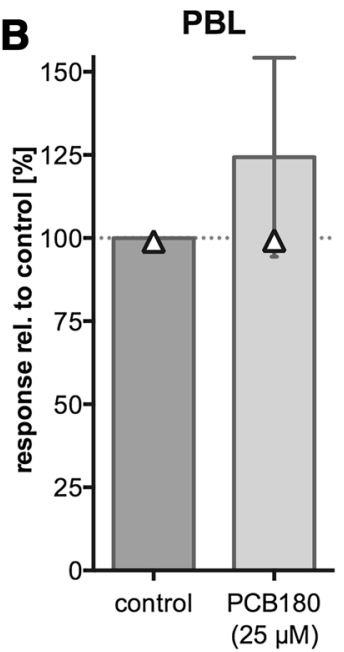

Cytochalasin D (CytoD, $100 \mathrm{nM})$ was used as positive control. Data are expressed as means $\pm \mathrm{SD}$ from two independent experiments. b Human peripheral blood lymphocytes (PBLs) were allowed to migrate in response to the chemokine CCL21 in transwell chemotaxis assays. Endpoint measurements different from the cMINC were chosen as PBLs migrate much faster compared to NCC and tumor cells. Viability of the cells was determined by TO-PRO $3^{\circledR}-3$ staining and flow cytometric counting. Migration was defined as the number of cells migrating within $1 \mathrm{~h}$ towards the chemokine CCL21 and is expressed relative to solvent control (0.25\% DMSO). Data are means \pm SD from three cell donors

of the ortho-chlorinated PCBs (Fig. 4c). Additionally, several approaches to antagonize retinoic acid receptors failed to show an effect (Fig. 4b, c). To gain evidence on whether PCBs may act as agonists on retinoic receptors, we compared the regulation of the receptors [which are downstream genes regulated by the retinoic receptor protein complexes (Bagamasbad and Denver 2011)] to the ones triggered by retinoic acid (RA) itself. While RA showed the expected responses, PCB180 had no effect (Fig. S3B).

Taken together, these data suggest that neither the AhR nor RyR, THR, and retinoic acid receptors are involved in PCB-induced migration-inhibition of NCC. We therefore developed an alternative strategy to identify potential targets that were affected by PCBs, and that mediated their effect on NCC migration. We reasoned that correlation of effects of a couple of compounds would not be sufficiently defining, given the multiple and complex cellular reactions towards PCBs (problem of overfitting). Therefore, we decided to test a larger number of PCBs, and to determine the SAR of PCBs concerning cMINC outcomes. We planned to compare this SAR with various PCB SARs known from the literature. Comparison of these SAR was expected to help to identify the most likely candidates for cellular processes affected by PCBs and being involved in migration-inhibition (Fig. 4d). 


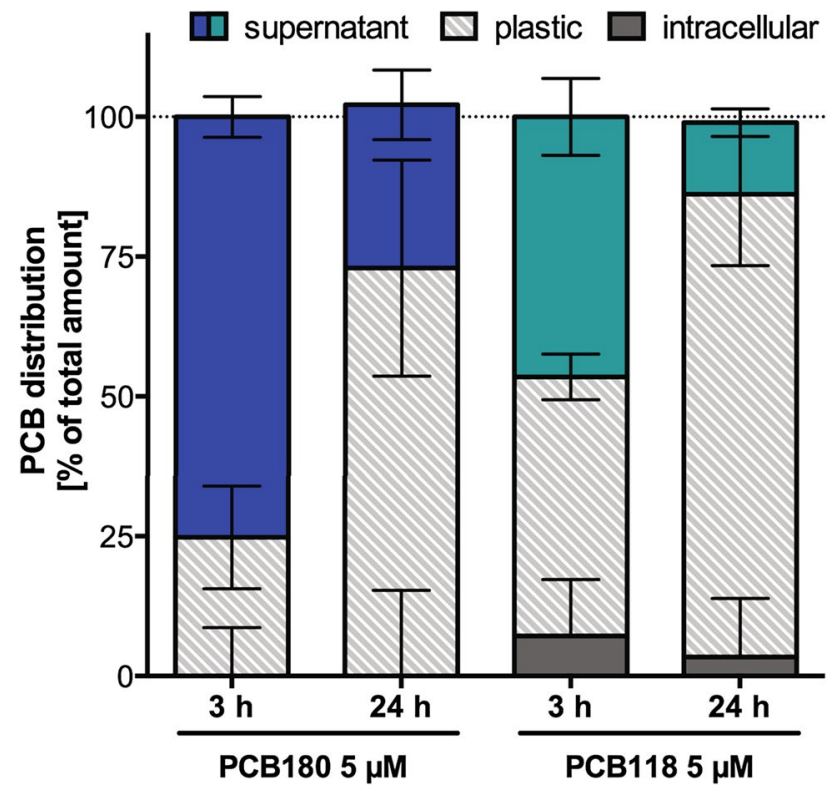

Fig. 3 Distribution of PCB in the culture dish. A PCB-solution $(5 \mu \mathrm{M})$ in cell culture medium was prepared in a low-absorbance vial, and its actual PCB content quantified and taken as 100\% reference value. Then, this solution was added to cell culture wells that were otherwise empty or that contained NCC under standard assay conditions. After 3 or $24 \mathrm{~h}$, samples were taken from the medium and assayed for PCB content. From the values obtained, the fractions of PCB absorbing to plastic (corresponding to the loss in dishes not containing cells), or accumulating in cells (difference of theoretical PCB content and the sum of content in supernatant and on plastic) was calculated. An example for reading the data is given for the $3 \mathrm{~h}$ incubation with PCB118: of the $5 \mu \mathrm{M}$ added, about $47 \%$ were recovered from the cell supernatant (remaining concentration of $2.3 \mu \mathrm{M}$ ), $46 \%$ of the toxicant adsorbed to plastic and about $7 \%$ was accumulated in cells. The experiment was performed three times and means \pm SD are shown

\section{Structure-activity relationship (SAR) of migration-inhibition by PCBs}

We assembled a set of 26 PCB congeners, containing 4-8 chlorine substitutions and $0-4$ ortho-chlorines. For all PCBs, the cMINC assay was run to generate concentration-response curves (Fig. S4, 5). The number of orthochlorines appeared to correlate with the potency of the compounds tested (Fig. 5a, b), with non-ortho PCB showing no effect at all up to concentrations of $40 \mu \mathrm{M}$. The 2- and 3 -ortho PCBs affected migration most efficiently, as they reduced migration by $\geq 80 \%$ at non-cytotoxic concentrations. Within the group of mono-ortho PCBs, the efficacy appeared to be reduced with an increasing degree of chlorination (Fig. 5a, b, Fig. S4, 5).

To confirm the cMINC data, cell tracking was performed for several of the congeners. All tested ortho-chlorinated PCBs significantly reduced cell speed by $>40 \%$ (Fig. 5c), while the non-ortho chlorinated PCB169 had no effect.
These data are in line with those obtained earlier (Fig. 1), but the few tested concentrations (lower throughput than the cMINC) did not reveal striking differences in efficacy. The most parsimonious and robust SAR-model supported by both assays is that "at least one ortho-chlorine is required for PCBs to inhibit NCC migration".

\section{Comparison of PCB effects on NCC migration with other PCB SARs}

Having established a SAR for migration, we followed the strategy outlined in Fig. 4d and searched for a feature that has the same SAR. For this purpose, a binary classification (active/inactive) was used to calculate the correlation of various features with cMINC data (Fig. 6a). First, we checked, whether simple physico-chemical descriptors (apart from biphenyl bond rotation angle and related parameters) indicated active or inactive PCB. However, molecular weight (MW), hydrophobicity $(\log \mathrm{P})$, apolar desolvation and polar desolvation energy did not differ significantly between the active and inactive PCBs (Fig. S6).

Next, we searched in the literature for data sets describing the effects of planar (non-ortho chlorine) vs non-planar (ortho-chlorine) PCBs on different receptors and cellular processes to calculate the correlation with cMINC data (Fig. S7). To complement the legacy data that showed sometimes large heterogeneity between assays and studies, we selected a subset of compounds for direct comparative measurements (Fig. S8). For generation of these data, reporter assays on the basis of luciferase expression in CALUX cells were used (Garrison et al. 1996; Sonneveld et al. 2005; van der Burg et al. 2015, 2013; van der Linden et al. 2014). All reporter constructs were integrated in the same cell line to allow comparison not only within assays, but also across different endpoints (Fig. 6b). Testing of PCBs in the CALUX system confirmed that concentrations up to $10 \mu \mathrm{M}$ were relatively well tolerated by cells. Moreover, measurements of two stress responses (endoplasmic reticulum stress and AP-1 activation) (van der Burg et al. 2013) showed that PCBs trigger such responses only at cytotoxic concentrations, but not in the non-cytotoxic range (Fig. S8). Thus, receptor activation information in our data set is most likely specific and independent of general cell toxicity.

The SAR on AhR activation and CYP1A induction reported in the literature (Al-Salman and Plant 2012; Hestermann et al. 2000) clearly did not match the SAR on NCC migration. Planar, non-ortho chlorinated PCBs are known to activate the AhR (Safe 1994), and these congeners were inactive on NCC migration. Our own data confirm the large activity difference (1000-fold) between highly potent (sub-nanomolar) planar and less potent non-planar PCB on CALUX cells (Fig. S8). Notably, these measurements also show that some (but not all) ortho-chlorine PCBs may 


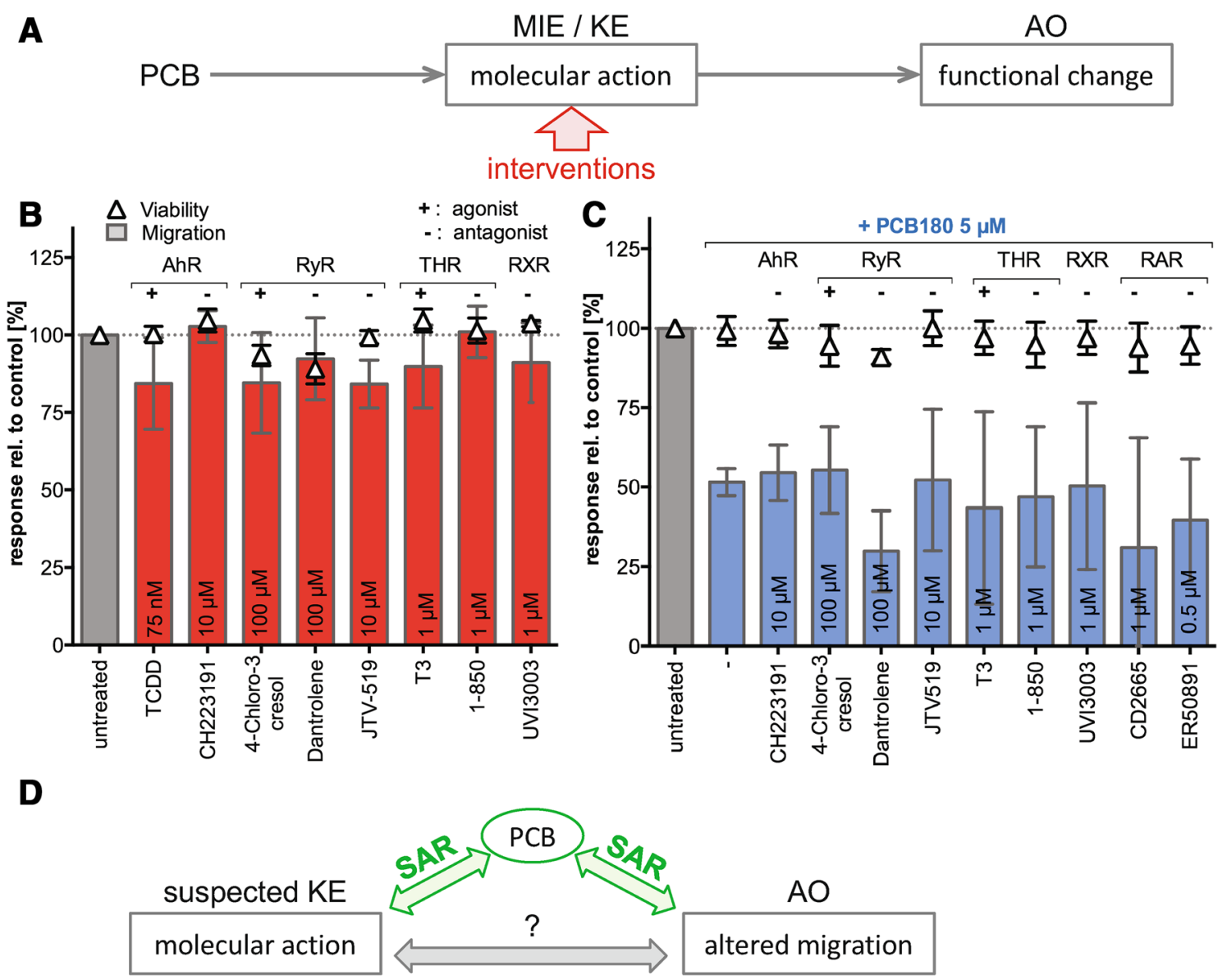

Fig. 4 Exploration of various signaling pathways as potential mediators of PCB toxicity to NCC. a Polychlorinated biphenyls (PCB) must lead to the observed functional change of NCC (i.e., lost capacity to migrate, as the adverse outcome (AO) relevant for developmental and reproductive toxicity) via some molecular action. Thus, we have to assume the triggering of some defined molecular initiating event (MIE) and subsequent key events (KE) that then lead to the AO. The graphical representation indicates how suspected MIE/KE may be probed by interventions with well-defined tool compounds. b Probing of suspected MIE/KE: NCC were used in the standard cMINC setup. Instead of PCBs, various inhibitors ( - ) and activators (+) of receptors were tested. The targets included the aryl hydrocarbon receptor $(\mathrm{AhR})$, the ryanodine receptor $(\mathrm{RyR})$, the thyroid hormone receptor (THR) and the retinoid-X receptor (RXR). Viability (open triangle) and migration (gray bars) are normalized to untreated controls. TCDD: 2,3,7,8-tetrachloro-dibenzodioxin. Data are expressed

activate the AhR in the submicromolar concentration range. Concerning the NCC, we found that migration-inhibiting non-planar PCBs did not increase CYP1 (downstream response of AhR activation) expression in NCC (in contrast to planar PCBs) (Fig. S3A).

The reported SAR for RyR binding and activation (Fritsch and Pessah 2013; Pessah et al. 2006) showed a good correlation with the NCC migration SAR. But as RyR agonists and antagonists did not affect NCC migration (Fig. 4b, c), RyR is unlikely to be the MIE for migration-inhibition in NCC. as means $\pm \mathrm{SD}$ from $\geq$ two independent experiments. c Effect of inhibitors of suspected receptors on inhibition of NCC migration (cMINC) triggered by PCB180 $(5 \mu \mathrm{M})$. Inhibitors where applied $1 \mathrm{~h}$ before PCB180. Test readout was after $24 \mathrm{~h}$ of PCB treatment. Viability (open triangles) and migration (blue bars) are normalized to untreated controls. $R A R$ retinoic acid receptor. Data are expressed as means \pm SD from two independent experiments. d Graphical representation of an alternative strategy to identify a mode-of-action (or at least one relevant $\mathrm{MIE} / \mathrm{KE}$ ) that is responsible for altered migration of NCC upon PCB exposure. Briefly, the approach would be based on the use of multiple PCBs and establishment of a structure-activity relationship (SAR) with respect to migration. This would then be compared to the SAR of PCB with respect to various suspected KE. If a sufficiently large number of PCB is chosen, then the overlap of the two SAR would be strongly suggestive of the respective KE being relevant to the $\mathrm{AO}$ (altered migration). (Color figure online)

Concerning nuclear receptors for steroids, several PCB SAR studies have been performed. Data are available for the AR, ER, THR, PXR and constitutive androstane receptor (CAR) (Al-Salman and Plant 2012; Hamers et al. 2011; Tabb et al. 2004). Literature and our own data on AR antagonism correlate well with cMINC data, while ER and related targets showed a poor correlation. AR antagonism was considered to be unlikely as MIE here, as stimulating ligands of the AR were not present in the test system. The same applies to PR antagonism. Concerning THR and retinoic receptors, 
A
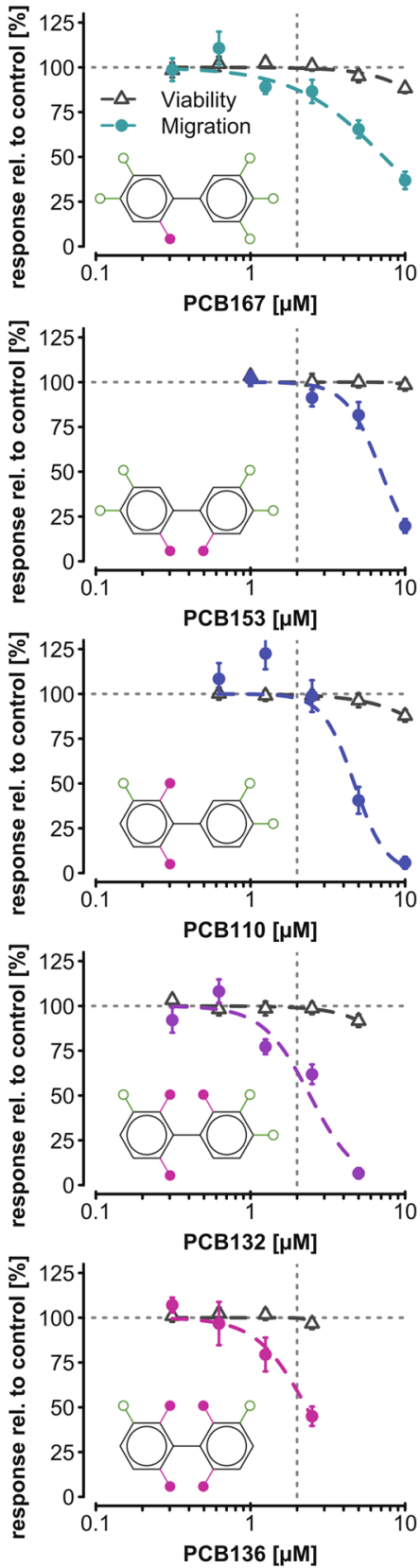

B

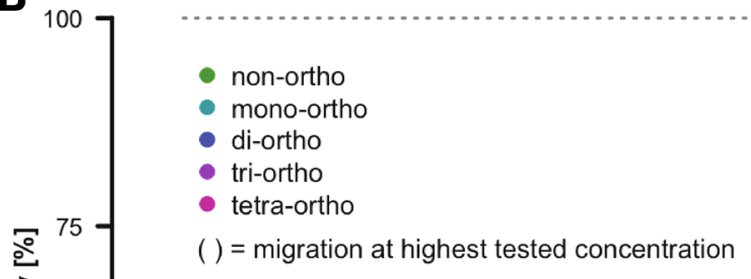

untreated
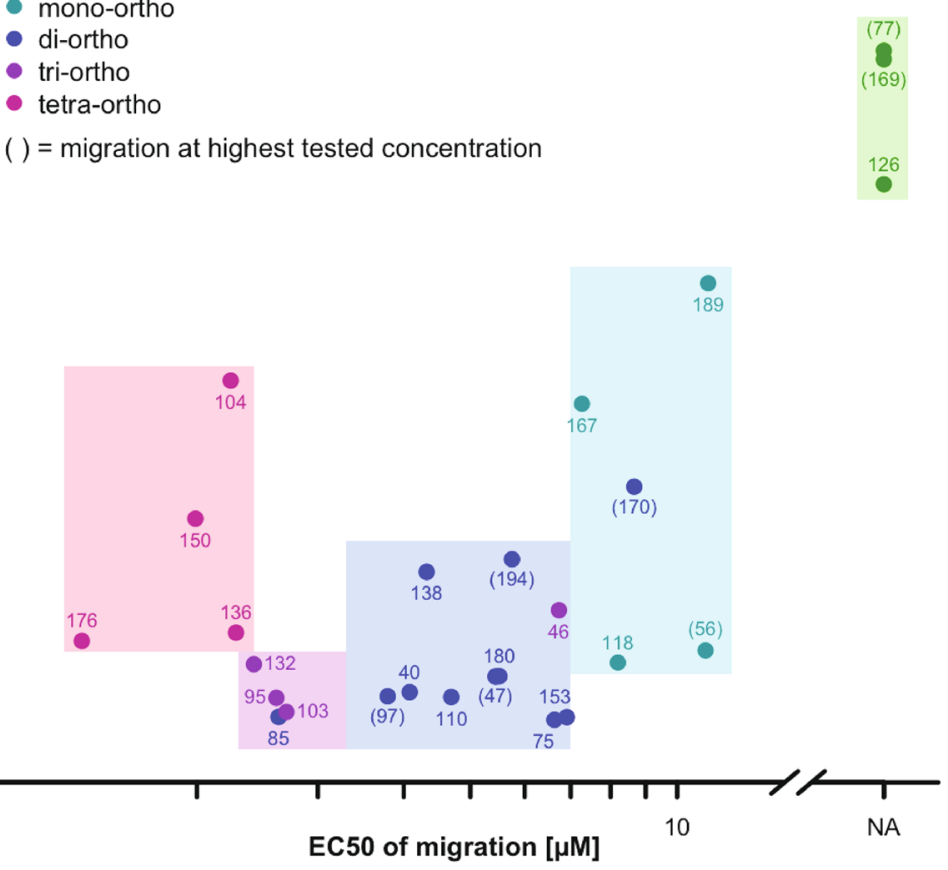

C

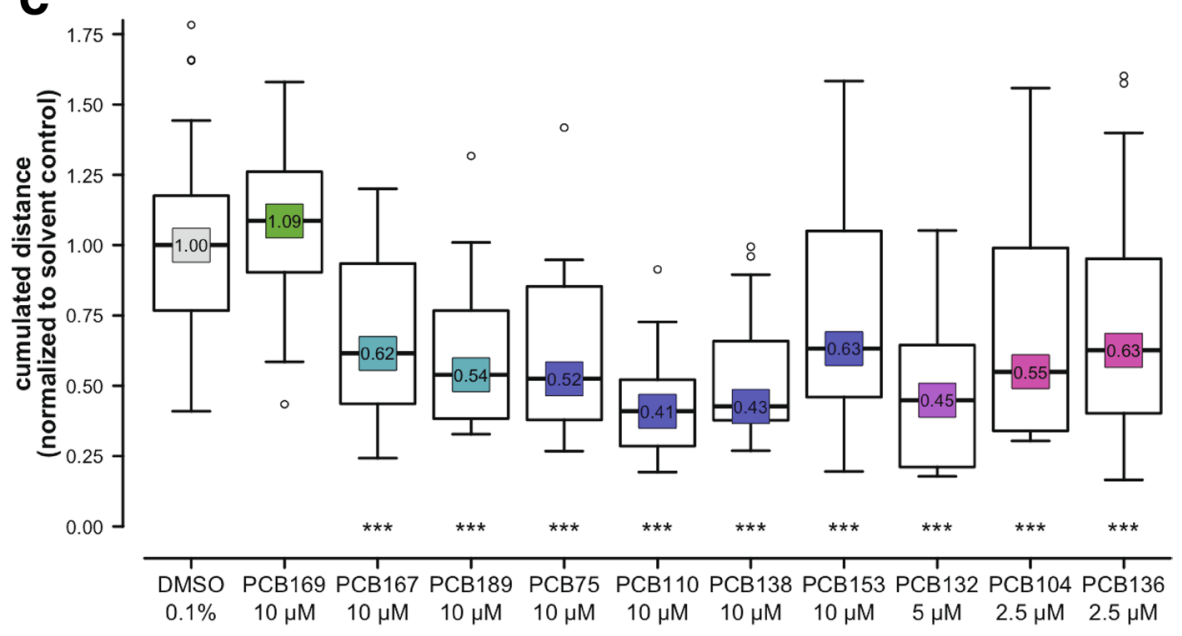

Fig. 5 Structure-activity relationship of $\mathrm{PCBs}$ and NCC migration. a Concentration-response curves of selected PCBs: the cMINC assay was used as in Fig. 1 to determine viability (open triangles) and migration (colored circles) under different experimental conditions. All data are normalized to those of untreated controls. For better visual comparison, the horizontal gray dotted line was plotted at $100 \%$; the vertical gray dotted line is at $2 \mu \mathrm{M}$. Data are expressed as means \pm SD from three independent experiments. Chemical structures are indicated with chlorine residues marked in purple (ortho position) or green (meta and para positions). b Overview of the effects of all tested PCBs on viability and migration. A log-logistic function with constraints was fitted to the concentration-response data of 26 PCBs. From these curves, the EC50 of migration and the \% migration at the EC90 of viability were determined and plotted against one another. For some PCBs, the EC90 of viability was not reached; in these cases, the migration at the highest tested concentration is shown. The color-shaded fields indicate areas of the scatterplot that are likely to harbor non-ortho PCB, mono-ortho PCB, di-ortho PCB, etc. $\mathbf{c}$ Effects of selected PCBs on individual cell speed. Time-lapse video microscopy was performed during the toxicant exposure, and the migration track of individual cells was identified. For each treatment condition, 8-12 individual cells were tracked and each cumulated travelled distance was normalized to the solvent control. Data from two biological replicates were pooled. The box represents the first and third quartiles, the black line the median (number given in the rectangle). The color code indicates the number of ortho-chlorine substituents. Statistical significance of differences between treated and non-treated conditions was calculated using a Wilcoxon rank sum test. Statistical indicators are given below the boxes: $* * * p<0.001$. (Color figure online) 
Fig. 6 Correlation of biochemical features of PCB with NCC toxicity. a Schematic representation of feature comparison. In a first step, a large group of PCBs is characterized as being active or inactive concerning effects on NCC migration. In a second step, literature data are obtained for the same PCB concerning various features that relate to a key event of a toxicity pathway/adverse outcome pathway (e.g., activation of the estrogen receptor). In the third step, the correlation of NCC activity and key events is examined for several candidate features (here shown as $X, Y, Z$, with correlations for the examples being indicated below). b A binary classification scheme was chosen to examine feature correlation. For each feature (with literature references indicated), it was determined, how many (\#) ortho PCB or non-ortho PCB were active or inactive. The correlation score (here called 'correct SAR') was calculated as: $100 \times(\#$ inactive non-ortho + \#active ortho)/total \# of PCB tested. The extent of correlation was color-coded (red: very good; blue: very poor). Abbreviations/feature definitions: AhR binding, binding to the aryl hydrocarbon receptor; Cyp1A1, cytochrome P4501A1; EROD activity, inhibition of cytochrome P450 (mainly Cyp1A family) enzymatic activity; $R y R$ ryanodine receptor; AR, androgen receptor, $E R$ estrogen receptor; E2SULT, estradiol sulfotransferase, TTR transthyretin, $P X R$ pregnane $\mathrm{X}$ receptor, $C A R$ constitutive androstane receptor, $D A T$ dopamine transporter, $G J$ gap junctions. (1) Hestermann et al. (2000); (2) Al-Salman and Plant (2012); (3) Pessah et al. (2006); (4) Fritsch and Pessah (2013); (5) Hamers et al. (2011); (6) Tabb et al. (2004); (7) Shain et al. (1991); (8) Mariussen et al. (2001); (9) Wigestrand et al. (2013); (10) Hemming et al. (1991). (Color figure online)
A

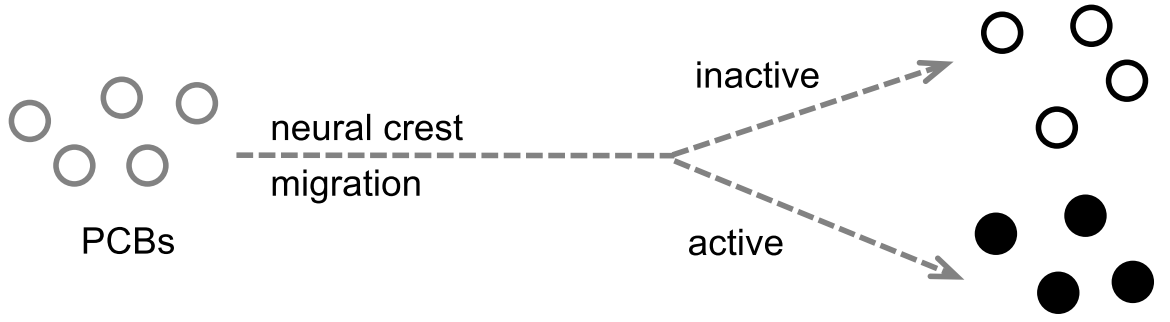

Key event alignment

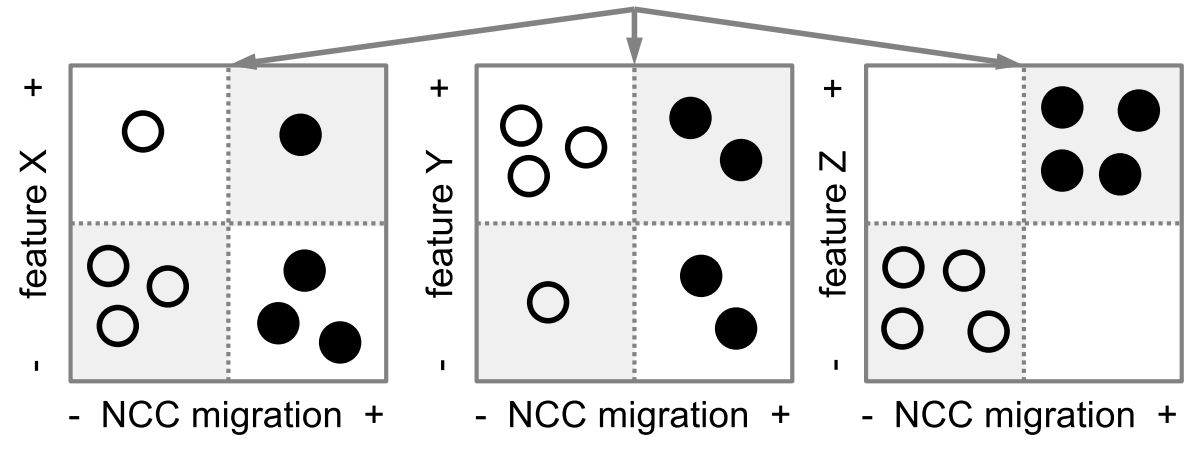

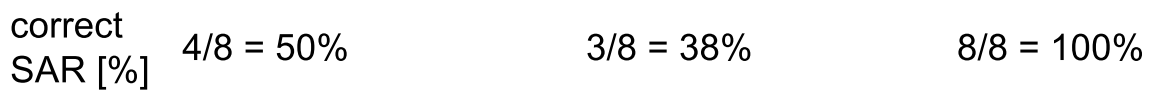

\begin{tabular}{|c|c|c|c|c|c|c|c|c|}
\hline \multirow{2}{*}{\multicolumn{2}{|c|}{ Feature }} & \multirow[t]{2}{*}{ Reference } & \multicolumn{2}{|c|}{ non-ortho } & \multicolumn{2}{|c|}{ ortho } & \multirow[b]{2}{*}{ total } & \multirow{2}{*}{$\begin{array}{l}\text { correct } \\
\text { SAR [\%] }\end{array}$} \\
\hline & & & \#active & \#inactive & \#active & $\#$ \#inactive & & \\
\hline & NCC migration & this study & 0 & 3 & 23 & 0 & 26 & 100 \\
\hline \multirow{5}{*}{$\frac{⿱}{\frac{\sigma}{L}}$} & AhR activation & this study & 2 & 0 & 5 & 5 & 12 & 42 \\
\hline & AHR binding & [1] & 4 & 0 & 4 & 0 & 8 & 50 \\
\hline & EROD activity & [1] & 4 & 0 & 2 & 2 & 8 & 25 \\
\hline & CYP1A induction & {$[1]$} & 4 & 0 & 2 & 2 & 8 & 25 \\
\hline & CYP1A1 induction & [2] & 1 & 0 & 0 & 5 & 6 & 0 \\
\hline \multirow{3}{*}{$\stackrel{\alpha}{\stackrel{\alpha}{\alpha}}$} & RyR1 binding (agonist) & {$[3]$} & 0 & 1 & 24 & 3 & 28 & 89 \\
\hline & RyR1 binding (antagonist) & [3] & 0 & 1 & 22 & 5 & 28 & 82 \\
\hline & RyR1 activation & [4] & 0 & 1 & 16 & 1 & 18 & 94 \\
\hline \multirow{16}{*}{ 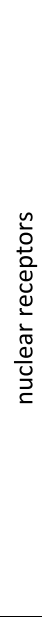 } & AR antagonism & this study & 2 & 0 & 10 & 0 & 12 & 83 \\
\hline & AR antagonism & {$[5]$} & 2 & 0 & 20 & 0 & 22 & 91 \\
\hline & ERa agonism & this study & 0 & 2 & 6 & 4 & 12 & 67 \\
\hline & ER agonism & {$[5]$} & 0 & 2 & 6 & 14 & 22 & 36 \\
\hline & ER antagonism & {$[5]$} & 0 & 2 & 5 & 15 & 22 & 32 \\
\hline & E2SULT inhibition & [5] & 0 & 2 & 12 & 8 & 22 & 64 \\
\hline & PR antagonism & this study & 1 & 1 & 10 & 0 & 12 & 92 \\
\hline & TTR binding & {$[5]$} & 1 & 1 & 8 & 12 & 22 & 41 \\
\hline & RAR activation & this study & 0 & 1 & 0 & 3 & 4 & 25 \\
\hline & RXR activation & this study & 0 & 1 & 0 & 3 & 4 & 25 \\
\hline & VDR activation & this study & 2 & 1 & 5 & 3 & 11 & 55 \\
\hline & PXR activation & this study & 0 & 2 & 10 & 0 & 12 & 100 \\
\hline & PXR activation & [2] & 0 & 1 & 4 & 1 & 6 & 83 \\
\hline & PXR activation & {$[6]$} & 0 & 1 & 3 & 3 & 7 & 57 \\
\hline & PXR antagonism & {$[6]$} & 0 & 2 & 15 & 6 & 23 & 74 \\
\hline & CAR activation & {$[2]$} & 0 & 1 & 4 & 1 & 6 & 83 \\
\hline \multirow{3}{*}{ 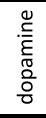 } & dopamine levels & [7] & 0 & 2 & 15 & 1 & 18 & 94 \\
\hline & dopamine uptake* & {$[8]$} & 1 & 3 & 23 & 1 & 28 & 93 \\
\hline & DAT binding & {$[9]$} & 0 & 1 & 23 & 2 & 26 & 92 \\
\hline \multirow{2}{*}{ ৩ } & GJ inhibition & [10] & 0 & 3 & 23 & 1 & 27 & 96 \\
\hline & GJ inhibition & [5] & 0 & 2 & 20 & 0 & 22 & 100 \\
\hline
\end{tabular}

B 
the SAR correlated poorly, and our functional data also did not support a role of these receptors (Fig. S3, Fig. 6). The same applies to the vitamin D receptor (VDR), for which we measured the induction. Several PCBs increased VDR expression levels, but since two non-ortho PCBs were active, while the three mono-ortho PCBs were inactive, we concluded that the VDR is not a likely MIE in NCC (Fig. S3C).

The SARs for CAR and PXR activation were very similar as the one for NCC migration (Fig. 6, Fig. S7, Fig. S8). This may be worth some further exploration in the future, but for the present study, we considered the likelihood of e.g., PXR being the MIE responsible for impaired migration as low. This is based on measurements of the expression level of the receptor on mRNA level: no transcripts were detectable in NCC (data below detection limit; not shown).

Several SARs for interference with the dopamine system have been reported (Mariussen et al. 2001; Shain et al. 1991; Wigestrand et al. 2013), all of them with good overlap to the SAR of NCC migration ( $>90 \%$ overlap). We ranked the likelihood of this mechanism as MIE as low, as NCC neither express tyrosine hydroxylase for synthesis of dopamine, nor do they express dopamine transporters (Zimmer et al. 2012).

Finally, PCBs are known to interfere with gap junctional intercellular communication (GJIC). Two studies reported a SAR, and in both cases, there was a high overlap (>95\%, only one mismatch) (Fig. 6). As NCC are known to express high levels of the gap junctional protein $\mathrm{Cx} 43$, and as GJIC is a well-established NCC feature (Boot et al. 2006; Huang et al. 1998; Li et al. 2007; Ruangvoravat and Lo 1992), we further investigated this hypothesis (see below).

Our approach of comparing SAR for different processes has several obvious weaknesses. Even though we did not match the numbers of actives and non-actives or weighted the data according to their uncertainty level, this coarse approach yielded some useful information that allowed ranking of likely candidate targets for PCBs, concerning causal involvement in cMINC effects. The GJIC was an initially surprising correlation, but considering all background information, it was regarded possible and sufficiently plausible to be further investigated.

\section{Investigation of gap junctional intercellular communication as target of PCB}

To measure GJIC in NCC, dye-transfer among neighboring NCC was assessed using the 'parachute assay' (adapted from Lecanda et al. 2000). NCC were cultured under standard cMINC conditions and treated with the PCBs for $24 \mathrm{~h}$ (Fig. 7a). Three hours before read-out, calcein-loaded (but otherwise untreated) donor NCC were parachuted (dropped as single cells) on top of the treated (acceptor) cultures (Fig. 7b). The assay is based on the fact that calcein spreads from donor to acceptor cells within $3 \mathrm{~h}$, if GJIC is functional.
The extent of dye-transfer into the acceptor layer was quantified using high-content imaging (Fig. 7c). Using this setup, the well-established GJIC blocker carbenoxolone showed the expected inhibitory effect (Fig. 7d). Additionally, PCB180 was found to strongly inhibit dye-transfer of NCC: only about $2 \%$ of donor cells spread their dye to PCB-treated acceptors. Altogether 26 PCBs were tested using this assay. Indeed, the non-ortho PCBs did not inhibit GJIC, while 11 of the ortho-chlorinated PCBs were efficient GJ inhibitors. However, 12 of the 23 migration-inhibiting PCBs did not inhibit GJIC (Fig. 7d). Obviously, the SAR concerning GJIC did not correlate well with inhibition of migration, and GJIC was therefore discarded as KE for migration-inhibition by PCBs.

In NCC, block of gap junctions may only occur with highly chlorinated PCBs, as the effect was observed with all compounds that had $\geq 2$ ortho-chlorines plus $\geq 2$ metachlorines (with one exception to that rule). The biochemical basis for this effect is unclear at present, but it may be linked to the higher hydrophobicity of these compounds. This may favor other interactions than those to the primary gap junction proteins (connexins). It is firmly established in the field of GJIC, that many effectors do not bind to connexins themselves, but rather affect their localization and post-translational modifications indirectly (Willebrords et al. 2017). For this reason, we still investigated other endpoints (e.g., gap junction protein localization) connected to gap junction structures.

\section{Changes in Cx43 localization as target of PCB for inhibition of NCC migration}

$\mathrm{Cx} 43$, the major connexin expressed in NCC, has been reported to affect NCC migration independent of its role in GJIC (Francis et al. 2011; Xu et al. 2001, 2006). To investigate whether PCBs may affect $\mathrm{Cx} 43$, we used immunocytochemical methods to investigate whether the toxicant affected protein localization. Confocal imaging revealed that $\mathrm{Cx} 43$ is localized mainly to the cell membrane and the Golgi. In untreated NCC, membranal Cx43 was mainly assembled in plaques ( $\mathrm{Cx} 43 \mathrm{pq})$, visible as bright spots on confocal images. Upon treatment with PCB180, the Cx43pq dissolved: $\mathrm{Cx} 43$ distributed more homogeneously along the cell membrane, and more of the protein seemed to be localized to the Golgi compared to controls (Fig. S9). Moreover, in silico docking and binding affinity prediction methods suggested that PCB180 and PCB153 bind with slightly higher affinity (39-40 kJ/mol) to Cx43 than, e.g., the planar PCBs 77 and $126(35-36 \mathrm{~kJ} / \mathrm{mol})$. For this reason, we felt that this should be explored further, and we established a high-content imaging assay for $\mathrm{Cx} 43 \mathrm{pq}$ quantification.

Our approach was based on immunofluorescence staining of NCC layers for $\mathrm{Cx} 43$. A thresholding plus segmentation 


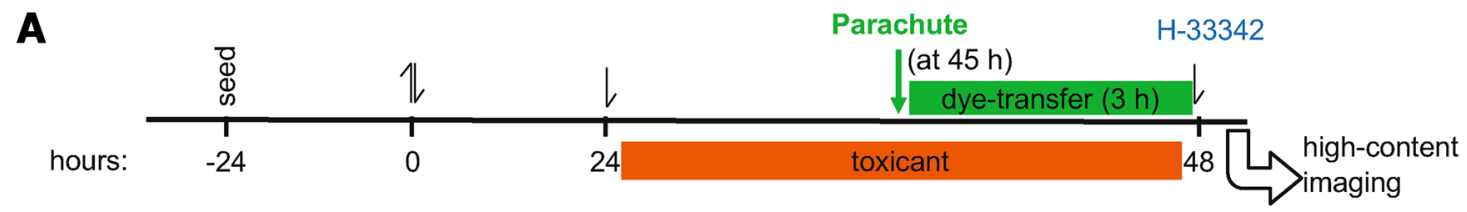

B

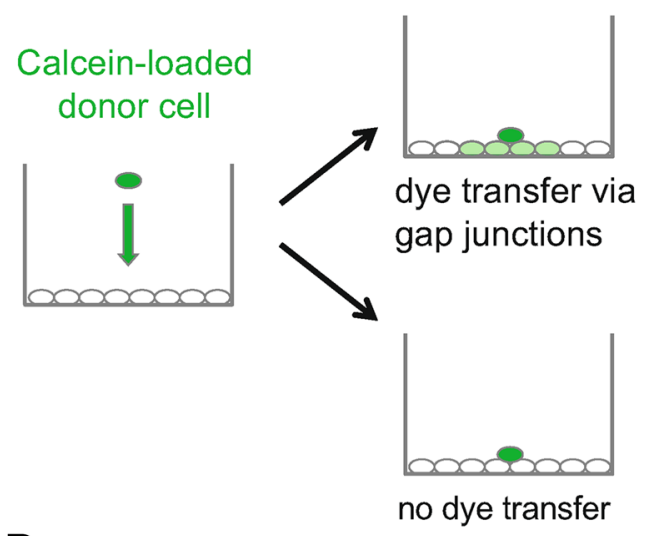

C

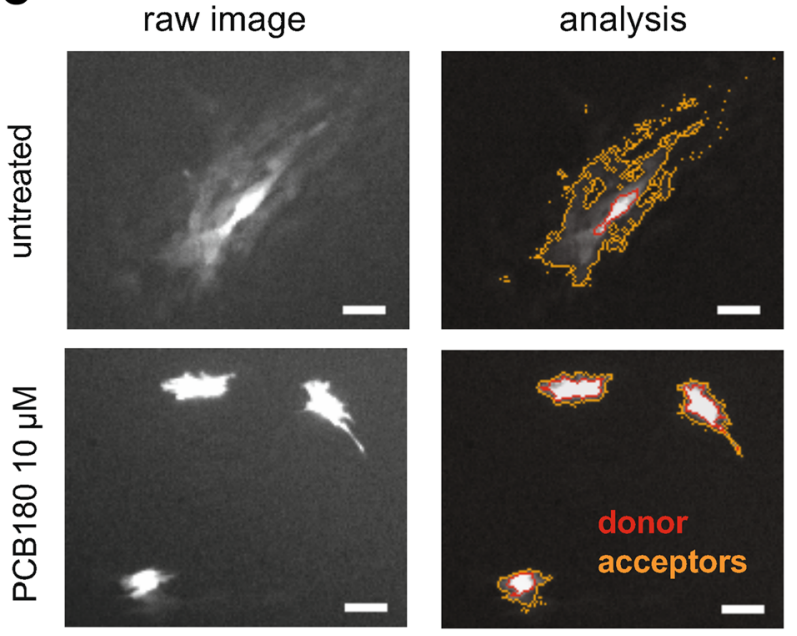

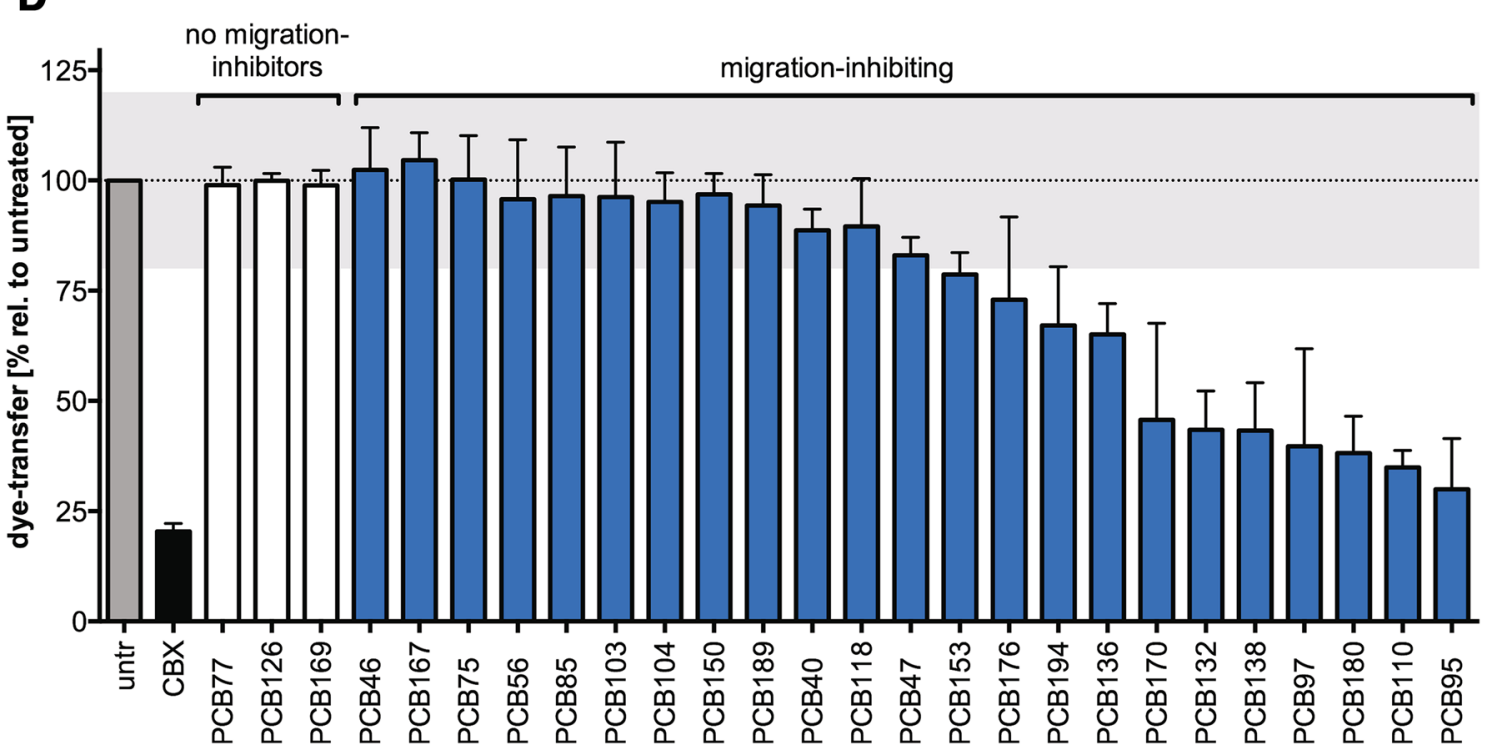

Fig. 7 Structure-activity relationship of PCBs and gap junctional communication. a Graphical representation of the experimental setup: cells were seeded in 24-well plates under conditions as for the cMINC assay. Test compounds were applied over night $(21 \mathrm{~h})$, and then calcein-stained donor cells were parachuted $(=$ dropped) on top of the treated cells. After that, calcein was allowed to spread from donor cells to the treated acceptor layer for $3 \mathrm{~h}$, before images were acquired. b Graphical representation of the parachuting step and two possible scenarios: transfer of dye to acceptors (top) or no transfer of dye (bottom). c Representative images (calcein channel) of cultures treated with PCB180 $(10 \mu \mathrm{M})$ or solvent control (untreated). Left:

algorithm was used to identify small, highly fluorescent protein dots. The number of these dots per image field was quantified (Fig. 8a). Using this assay, we found that the raw image; right: result of the quantification. Donor cells (identified by bright fluorescence) are marked in red (one on top, three in the bottom example); the area in the acceptor cell layer that was labeled by calcein is demarcated by orange lines. Scale bar is $50 \mu \mathrm{m}$. d Performance of PCBs in the parachute assay. Dye-transfer is normalized to untreated control. The gray zone indicates the noise level (=1 SD) of solvent controls. Carbenoxolone (CBX) was used as an endpointspecific control for gap junction inhibition. Data are expressed as means \pm SEM from three independent biological experiments. (Color figure online)

gap junction blocker carbenoxolone quickly (within $2-3 \mathrm{~h}$ ) reduced the $\mathrm{Cx} 43 \mathrm{pq}$, and the same effect was observed with the migration-inhibitory PCBs 180 and 118 within a similar 

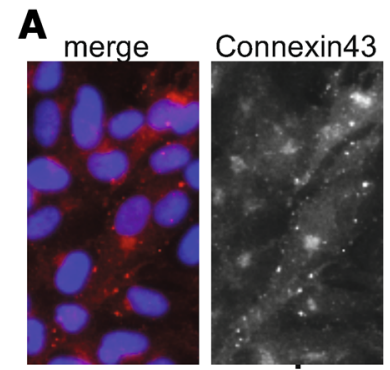

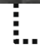

\section{B}

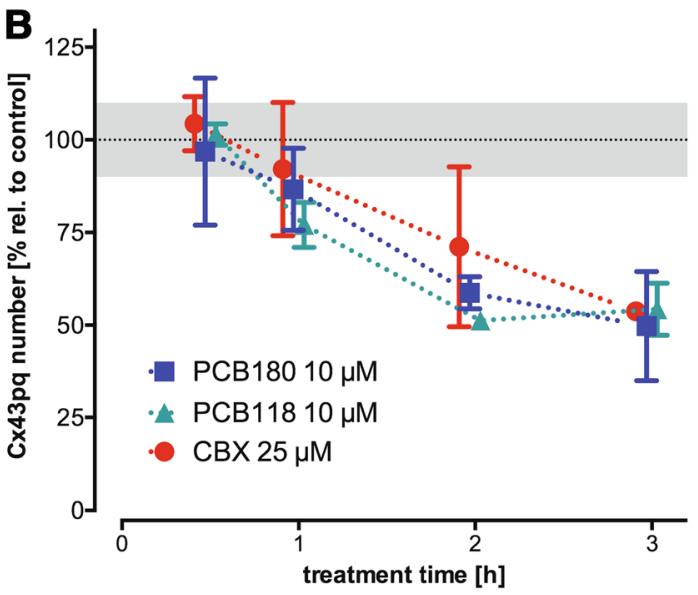

D

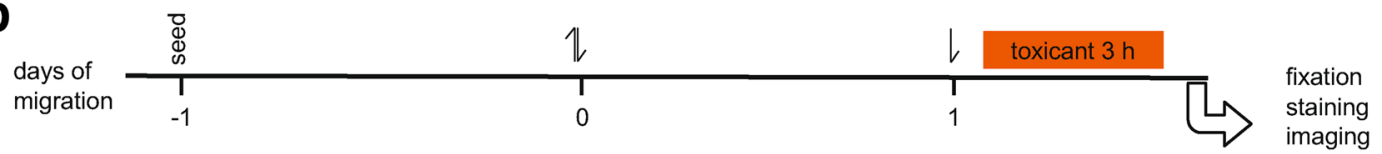

\section{E}

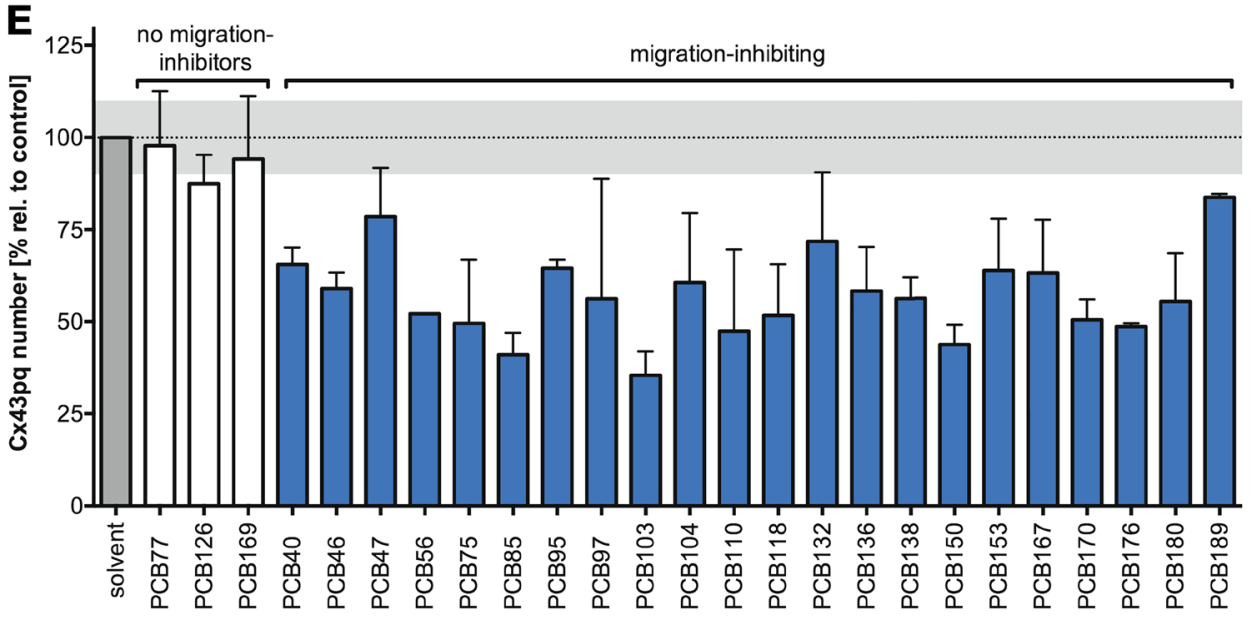

Fig. 8 Connexin43 localization and quantification of 'connexin43 plaques'. a Quantification algorithm of Cx43pq. Cells were stained (H-33342) for DNA (blue nuclei) and connexin43 (red) and imaged on an epifluorescence microscope. The connexin 43 channel was thresholded to only display the brightest pixels ( $>80 \%$ of maximal intensity, displayed here in inverted mode), followed by a segmentation and size (area) filtering of the bright spots (here displayed in black). Objects of $<10$ pixels size were scored (=valid objects). For visualization, the valid objects (red) were overlaid on the greyscale connexin43 image. b Example for toxicant-induced changes in the number of $\mathrm{Cx} 43 \mathrm{pq}$ (small bright dots). Cells were seeded on glass bottom plates under cMINC assay conditions. They were exposed to test compounds for the times indicated, before they were fixed and stained. Then, the quantification procedure detailed above was applied, and data were normalized to solvent controls. c Quantification of $\mathrm{Cx} 43 \mathrm{pq}$ upon treatment with various concentrations of exemplary toxicants. The experiment was performed as in $\mathbf{b}$, but all quantifications were performed after $3 \mathrm{~h}$. d Graphical representation of the experimental setup for the $\mathrm{Cx} 43 \mathrm{pq}$ assay: Cells were seeded on glass bottom plates under cMINC conditions, and $\mathrm{Cx} 43 \mathrm{pq}$ were quantified at $3 \mathrm{~h}$ after toxicant exposure. e Following the above exposure scheme, three planar and 22 non-planar PCB were tested for reduction in Cx43pq. The gray zone indicates the noise level (=1 SD) of solvent controls. Data are expressed as means \pm SD from two independent biological experiments. (Color figure online) 
time scale and to the same extent (Fig. 8b). This fast effect of PCBs is well in line with our observations from cell tracking, that PCB treatment slowed down cell movement within few hours. GJIC-independent effects of $\mathrm{Cx} 43$ that could be affected are, e.g., the role of the protein for the stability of leading processes of migrating cells (Elias et al. 2007).

Recording of concentration-response curves revealed, that the reduction of $\mathrm{Cx} 43 \mathrm{pq}$ follows the same concentration dependency as inhibition of migration in the cMINC. For instance, the 4-ortho chlorinated PCB104 was more potent than PCBs 180 and 118 (Fig. 8c). Encouraged by these findings, our whole set of PCBs was screened in the $\mathrm{Cx} 43 \mathrm{pq}$ assay at a fixed time point ( 3 h) (Fig. 8d).

All migration-inhibiting PCBs reduced $\mathrm{Cx} 43 \mathrm{pq}$, whereas the three non-ortho PCBs did not have an effect (Fig. 8e). Thus, the observed SAR for $\mathrm{Cx} 43$ localization was identical to the SAR for NCC migration-inhibition. This is not necessarily due to direct binding of PCB to $\mathrm{Cx} 43$, as in silico estimation of binding energies of all PCBs to $\mathrm{Cx} 43$ did not reveal a correlation between predicted affinities and inhibited migration or reduced $\mathrm{Cx} 43 \mathrm{pq}$ (not shown). Nevertheless, the correlation of the SAR across compounds between cMINC results and the Cx43pq assay (Fig. 9) was statistically significant ( $p<0.0004$ for a random association), so that we concluded $\mathrm{Cx} 43$ mislocalization represents an early $\mathrm{KE}$ involved in the PCB-induced inhibition of NCC migration.

\section{Discussion}

We tested PCBs, as a group of environmentally relevant toxicants, and found that all tested ortho-chlorinated PCBs inhibited NCC migration, whereas non-ortho chlorinated, dioxin-like PCBs were ineffective. As investigation of several pathways known to be targeted by PCBs did not reveal the mechanism of migration-inhibition, we employed a new strategy and established a SAR for migration-inhibition and compared it to the literature data. According to the literature, GJIC appeared initially as a process that might explain the effects of PCB on NCC migration, but the SAR for GJIC had only an overlap of $50 \%$ with the SAR for migration-inhibition (Fig. 9). However, examinations of GJIC let us consider Cx43 localization. The SAR for this feature was identical to the one for migration-inhibition. Therefore, $\mathrm{Cx} 43$ localization seems to be a mechanistic step tightly linked to NCC toxicity of PCBs.

Previous studies found that PCB153 reduces localization features of $\mathrm{Cx} 43$ at the plasma membrane of epithelial cells (Kang et al. 1996; Simeckova et al. 2009). In the present study, we found that all tested ortho-chlorinated PCBs reduced Cx43pq in human NCC. Our observations do not provide proof that $\mathrm{Cx} 43$ mislocalization is causing the observed inhibition of migration, but the probability that the two SARs would overlap completely by chance is $<0.0004$.

To our knowledge, there are no other reports about $\mathrm{Cx} 43$ mislocalization in the context of migration-inhibition. However, several studies have reported that knock-down or knock-out of $\mathrm{Cx} 43$ reduces migration of NCC (Huang et al. 1998; Xu et al. 2006) and neural cells (Cina et al. 2009; Elias et al. 2007; Fushiki et al. 2003; Wiencken-Barger et al. 2007). Several studies also concluded that $\mathrm{Cx} 43$ affects NCC migration in a GJ-independent manner (Francis et al. 2011; $\mathrm{Xu}$ et al. 2001, 2006). The C-terminal tail of $\mathrm{Cx} 43$ was reported to be important for promoting migration in neural cells (Bates et al. 2007; Behrens et al. 2010; Cina et al. 2009; Crespin et al. 2010; Elias et al. 2007). Francis et al. (2011) showed, that NCC expressing a Cx43 variant lacking the C-terminal tubulin-binding domain $(\mathrm{Cx} 43 \Delta \mathrm{T})$ tend to migrate less. Other studies with NCC and other cell types concluded, that $\mathrm{Cx} 43$ knock-out cells fail to realign their microtubule organizing center and Golgi in the direction of migration. Additionally, loss of stabilized microtubules and alterations in the actin skeleton were observed (Francis et al. 2011; Rhee et al. 2009; Xu et al. 2006).

The present experiments do not allow conclusions on whether Cx43 is the primary target of PCBs in NCC, and whether the reduction of $\mathrm{Cx} 43 \mathrm{pq}$ is causal to the adverse outcome of reduced migration. Alternatively, reductions of Cx43pq may be a biomarker for another, yet unknown KE triggered by PCBs. For example, blocking of cell adhesion

\begin{tabular}{|l|c|c|c|c|c|c|}
\hline \multirow{2}{*}{ Feature } & \multicolumn{2}{|c|}{ non-ortho } & \multicolumn{2}{|c|}{ ortho } & & \multicolumn{1}{c|}{$\begin{array}{c}\text { correct } \\
\text { SAR [\%] }\end{array}$} \\
\cline { 2 - 7 } & \#active & \#inactive & \#active & \#inactive & total & SA [ \\
\hline inhibit migration (cMINC assay) & 0 & 3 & 23 & 0 & 26 & 100 \\
\hline decrease cell speed & 0 & 2 & 11 & 0 & 13 & 100 \\
\hline inhibit gap junctional communication & 0 & 3 & 11 & 12 & 26 & 54 \\
\hline decrease Cx43pq & 0 & 3 & 22 & 0 & 25 & 100 \\
\hline
\end{tabular}

Fig. 9 Overview of structure-activity relationships of PCBs. The tested PCB had similar effects on migration and on connexin43 plaques (Cx43pq; 100\% correlation). A high correlation with reduced cell speed was also observed (but only about half of the compounds were tested). In contrast to this, inhibition of gap junction communication (parachute assay) did not correlate well with migration or with $\mathrm{Cx} 43 \mathrm{pq}$ 
or knock-out of ephrin-B1 can lead to relocation of $\mathrm{Cx} 43$ (Davy et al. 2006; Guo et al. 2003). Moreover, Cx43 can bind to the tight junction protein ZO-1, and interaction with ZO-1 can affect GJ plaque size, trafficking and turnover of Cx43 (Giepmans and Moolenaar 1998; Hunter et al. 2005).

At present, it is not entirely clear how PCBs lead to the reduction of $\mathrm{Cx} 43 \mathrm{pq}$, and whether it is likely that they bind directly to $\mathrm{Cx} 43$. Our in silico docking studies did not find a clear correlation of calculated PCB-Cx43 binding energies and neither migration or plaque formation. Although this approach is associated with several uncertainties, it suggests that it is likely that other or additional targets are affected by PCB in NCC. Such alternative binding partners could lead to a reduction of $\mathrm{Cx} 43 \mathrm{pq}$ either by promoting transport away from the membrane or by attenuating the transport to the membrane. In the first scenario, either internalization and degradation via lysosomes, or proteasomal degradation, leading to destabilization of phosphorylated Cx43 at the membrane or endoplasmatic reticulum-assisted degradation might be enhanced (Laird 2005; Qin et al. 2003; Simeckova et al. 2009). In the second scenario, less protein production or less protein transport to the membrane could be the cause. Moreover, $\mathrm{Cx} 43 \mathrm{pq}$ could be reduced if $\mathrm{Cx} 43$ is present at the membrane, but not assembled in plaques.

In our experiments, there was no evidence for disturbed protein production. Firstly, mRNA levels of $\mathrm{Cx} 43$ were not affected by PCB treatment (Fig. S10B). Secondly, in immunofluorescent stainings, $\mathrm{Cx} 43$ was clearly visible, but seemed to be more accumulated in the Golgi, particularly after longer treatment periods (data not shown). These data rather indicate that transport could be disturbed or endoplasmatic reticulum-assisted degradation could take place. As cell function control, we measured membrane protein sialyation, a process that requires the functioning of protein synthesis, and several complex processing and intracellular translocation steps. PCB exposure did not affect localization or abundance of glycoproteins (Fig. S1). Moreover, two inhibitors of protein processing and transport (brefeldin A, tunicamycin) did not appear to decrease $\mathrm{Cx} 43 \mathrm{pq}$ (data not shown). These results indicate that PCB treatment does not affect transport of proteins and lipids in general. But we cannot rule out that PCBs affect specifically transport of Cx 43 to the membrane.

Other studies report that PCB153 does not affect the mRNA level of $\mathrm{Cx} 43$ but reduces the level of phosphorylated Cx43 in epithelial cells (Bager et al. 1997b; Kang et al. 1996; Simeckova et al. 2009). Phosphorylation of $\mathrm{Cx} 43$ is involved in its turnover and subcellular localization (Guo et al. 2003; Laird et al. 1995). Simeckova et al. (2009) suggest that PCB153 disturbs protein transport to the plasma membrane, as PCB-treated cells recovering from brefeldin A treatment take longer to restore GJIC. Moreover, they suggest that the lysosomal pathway is involved in PCB-induced degradation of $\mathrm{Cx} 43$. Whether these processes are also relevant for NCC, and whether they play a role for the effect of PCB on their migration, requires an extensive and meticulous follow-up study.

Are there mechanistic explanations for our observation that all ortho-PCBs reduced $\mathrm{Cx} 43 \mathrm{pq}$, but only some inhibited GJIC? In this context, it should be noted, that our SAR for GJIC - based on 26 PCBs with varying chemical properties-differs from the two reported SARs in the literature (Hamers et al. 2011; Hemming et al. 1991). This is not entirely unexpected, as SARs for such complex endpoints like migration and GJIC may be cell-specific. For instance, some PCBs may have direct targets within GJ of all cell types, while a subgroup of PCBs may affect cell-specific pathways or protein complexes that impact then on GJIC as downstream process. Both published studies used a rat liver epithelial cell line (WB-F344) to evaluate altogether 39 PCBs. In contrast to us they found that all (except for PCB189) ortho-chlorinated PCBs inhibited GJIC (Fig. S7).

When comparing SAR for different cell types, it should be considered that GJIC is only blocked if all (or most) GJ are blocked, and that the outcome of the tests depends on the sensitivity of the assay and on how the threshold for inhibition of GJIC is defined. For block of GJIC in NCC, this would mean that $\mathrm{Cx} 43$-based GJ, and also some others, need to be blocked. NCC express at least one other connexin, Cx45 (Fig. S10A). It is possible that some orthoPCBs inhibit GJ of both connexins, and thus block GJIC in NCC. Other ortho-PCBs may interfere only with $\mathrm{Cx} 43$. This would explain why the SAR of GJ inhibition and Cx43 localization differ. Finally, it is important to consider, whether the immunopositive spots identified by our immunostain truly represented $\mathrm{Cx} 43$. We are convinced that the spots are indeed $\mathrm{Cx} 43$, because the observed localization at the membrane and in spots matches exactly with what has been reported for $\mathrm{Cx} 43$ (Langlois et al. 2010; Lemcke et al. 2013; Simeckova et al. 2009). Moreover, we tested two different antibodies and both resulted in the same pattern. The antibodies stained three bands at $37-40 \mathrm{kDa}$ in Western blots, exactly what is reported for Cx43 (Fiorini et al. 2008; Guan and Ruch 1996; Kang et al. 1996; Matesic et al. 1994). Quantification of Cx43 levels by Western blotting showed that NIH-3T3 cells expressed high levels (consistent with earlier publications), while MDA-MB-231, HEK293 and Hela cells expressed very low levels (data not shown). These data suggest that the presence of $\mathrm{Cx} 43$ as such is not sufficient to allow PCB toxicity (in NIH-3T3 cells). The cells need to express the machinery regulating the re-localization of $\mathrm{Cx} 43$ upon PCB exposure, and they also need to express the machinery that translates the change in $\mathrm{Cx} 43$ distribution to an altered migration capacity. All three conditions seem to be fulfilled only in NCC. 
To summarize, the present study revealed that ortho-chlorinated $\mathrm{PCBs}$ are strongly migration-inhibiting for human NCC and that the effect is closely correlated to a mislocalization of $\mathrm{Cx} 43$. To the best of our knowledge, this is the first report of migration-inhibition by non-planar PCBs. It also appears that the effect is limited to NCC or to only few cell types, as typical cell lines did not react to the tested PCBs. By testing a set of PCBs and establishing a SAR for NCC migration-inhibition, we could compare to SARs available in the literature and came up with a possible mechanism.

Notably, exploration of this comparative SAR approach for mechanistic and investigative toxicology was the main intention of this study. In this context, it should be noted that the effects observed here in vitro occur at micromolar concentrations (or marginally lower, if plastic adsorption is considered). They are thus rather not relevant for general environmental exposure of the population. Such levels would rather reflect special cases such as accidental or intentional human poisoning, or exposure of small subgroups of subjects in exceptional work situations (Pierucci et al. 2017; Ziegler et al. 2017). The mechanism identified here for such a focused scenario may apply more broadly to other toxicant classes relevant for human safety. The two NCC migrationinhibitors DDT and dieldrin were found to reduce $\mathrm{Cx} 43 \mathrm{pq}$ in other cell types (Kang et al. 1996) and are thus candidates for further investigations in our model system. Although our SAR is relatively extensive, further extensions could provide new information. For instance, PCBs with very low chlorination state have not been considered here, and neither have non-ortho chlorinated PCBs that are not dioxin-like.

A straightforward way for validation of the in vivo relevance of our study results would be comparison to the respective effects in animal models. One would imagine that such data should be available, as this group of compounds has been studied intensively. However, most data were obtained on PCB mixtures, and nearly all studies on individual compounds used planar PCBs. We could not find any in vivo study on non-planar PCBs in appropriate concentrations. It would be highly interesting to obtain such data, for example, using zebrafish, a model species in which NCC can express fluorescent proteins that allow monitoring of migration. Offspring could be analyzed for craniofacial malformations, disorders of the peripheral or enteric nervous system or behavioral abnormalities (as NCC build the adrenal medulla). If the NCC migration-inhibiting effect is as strong in vivo as observed in our in vitro experiments, the treatment could result in embryonic lethality.

A future extension of the SAR approach explored here could be to use transcriptome data, instead of published findings. Since PCBs are likely to induce many transcriptome changes, a large number of congeners would need to be tested to identify consensus changes that correlate with a phenotypic adverse effect. This way, noise could be filtered from signal in transcriptome data sets. This would probably not have been possible by use of classical transcriptomics technology, as used in one of our previous studies (Pallocca et al. 2017) due to limiting resources. However, new highthroughput transcriptomics approaches (Yeakley et al. 2017) make this approach possible, for instance in the context of the EU-ToxRisk project (Daneshian et al. 2016). Thus, the double-SAR strategy to find a mechanistic step tightly linked to NCC toxicity of PCBs, could become a general tool for identification of toxicity mechanisms.

Acknowledgements This work was supported by the Land BW, the Doerenkamp-Zbinden foundation, the DFG (RTG1331, KoRS-CB) and the European Project EU-ToxRisk. We are grateful to M. Kapitza, H. Leisner, K. Semperowitsch, M. Brüll, the staff of the University of Konstanz bioimaging center (BIC) and the flow cytometry center (FlowKon) for invaluable experimental support. EG acknowledges support by the Fonds Nationale de la Recherche (FNR) through the National Centre of Excellence in Research (NCER) on Parkinson's disease (I1R-BIC-PFN-15NCER). Computational analyses presented in this paper were carried out in part using the HPC facilities of the University of Luxembourg (see http://hpc.uni.lu).

\section{Compliance with ethical standards}

Conflict of interest The authors declare no conflict of interest.

\section{References}

Al-Salman F, Plant N (2012) Non-coplanar polychlorinated biphenyls (PCBs) are direct agonists for the human pregnane-X receptor and constitutive androstane receptor, and activate target gene expression in a tissue-specific manner. Toxicol Appl Pharmacol 263:7-13. https://doi.org/10.1016/j.taap.2012.05.016

Arvan P, Zhao X, Ramos-Castaneda J, Chang A (2002) Secretory pathway quality control operating in Golgi, plasmalemmal, and endosomal systems. Traffic 3:771-780

Aschner M et al. (2017) Reference compounds for alternative test methods to indicate developmental neurotoxicity (DNT) potential of chemicals: example lists and criteria for their selection and use. ALTEX 34:49-74 https://doi.org/10.14573/altex.1604201

Bagamasbad P, Denver RJ (2011) Mechanisms and significance of nuclear receptor auto- and cross-regulation. Gen Comp Endocrinol 170:3-17. https://doi.org/10.1016/j.ygcen.2010.03.013

Bager Y, Kenne K, Krutovskikh V, Mesnil M, Traub O, Wärngàrd L (1994) Alteration in expression of gap junction proteins in rat liver after treatment with the tumour promoter $3,4,5,3^{\prime}, 4^{\prime}$-pentachiorobiphenyl. Carcinogenesis 15:2439-2443. https://doi.org/10.1093/ carcin/15.11.2439

Bager Y, Kato Y, Kenne K, Warngard L (1997a) The ability to alter the gap junction protein expression outside GST-P positive foci in liver of rats was associated to the tumour promotion potency of different polychlorinated biphenyls. Chem Biol Interact 103:199-212

Bager Y, Lindebro MC, Martel P, Chaumontet C, Warngard L (1997b) Altered function, localization and phosphorylation of gap junctions in rat liver epithelial, IAR 20, cells after treatment with PCBs or TCDD. Environ Toxicol Pharmacol 3:257-266 
Bates DC, Sin WC, Aftab Q, Naus CC (2007) Connexin43 enhances glioma invasion by a mechanism involving the carboxy terminus. Glia 55:1554-1564. https://doi.org/10.1002/glia.20569

Behrens J, Kameritsch P, Wallner S, Pohl U, Pogoda K (2010) The carboxyl tail of $\mathrm{Cx} 43$ augments p38 mediated cell migration in a gap junction-independent manner. Eur J Cell Biol 89:828-838. https://doi.org/10.1016/j.ejcb.2010.06.003

Boot MJ, Gittenberger-de Groot AC, Poelmann RE, Gourdie RG (2006) Connexin43 levels are increased in mouse neural crest cells exposed to homocysteine. Birth Defects Res A Clin Mol Teratol 76:133-137. https://doi.org/10.1002/bdra.20220

Brevini TA, Vassena R, Paffoni A, Francisci C, Fascio U, Gandolfi F (2004) Exposure of pig oocytes to PCBs during in vitro maturation: effects on developmental competence, cytoplasmic remodelling and communications with cumulus cells. Eur J Histochem 48:347-356

Choi W, Eum SY, Lee YW, Hennig B, Robertson LW, Toborek M (2003) PCB 104-induced proinflammatory reactions in human vascular endothelial cells: relationship to cancer metastasis and atherogenesis. Toxicol Sci 75:47-56. https://doi.org/10.1093/ toxsci $/ \mathrm{kfg} 149$

Cina C, Maass K, Theis M, Willecke K, Bechberger JF, Naus CC (2009) Involvement of the cytoplasmic C-terminal domain of connexin43 in neuronal migration. J Neurosci 29:2009-2021. https:// doi.org/10.1523/JNEUROSCI.5025-08.2009

Crespin S, Bechberger J, Mesnil M, Naus CC, Sin WC (2010) The carboxy-terminal tail of connexin43 gap junction protein is sufficient to mediate cytoskeleton changes in human glioma cells. J Cell Biochem 110:589-597. https://doi.org/10.1002/jcb.22554

Daneshian M, Kamp H, Hengstler J, Leist M, van de Water B (2016) Highlight report: launch of a large integrated European in vitro toxicology project: EU-ToxRisk. Arch Toxicol 90:1021-1024. https://doi.org/10.1007/s00204-016-1698-7

Davy A, Bush JO, Soriano P (2006) Inhibition of gap junction communication at ectopic Eph/ephrin boundaries underlies craniofrontonasal syndrome. PLoS Biol 4:e315. https://doi.org/10.1371/ journal.pbio.0040315

Dreser N et al (2015) Grouping of histone deacetylase inhibitors and other toxicants disturbing neural crest migration by transcriptional profiling. Neurotoxicology 50:56-70. https://doi.org/10.1016/j. neuro.2015.07.008

Du J, Meledeo MA, Wang Z, Khanna HS, Paruchuri VD, Yarema KJ (2009) Metabolic glycoengineering: sialic acid and beyond. Glycobiology 19:1382-1401. https://doi.org/10.1093/glycob/cwp115

Elias LA, Wang DD, Kriegstein AR (2007) Gap junction adhesion is necessary for radial migration in the neocortex. Nature 448:901907. https://doi.org/10.1038/nature06063

Ferris SP, Kodali VK, Kaufman RJ (2014) Glycoprotein folding and quality-control mechanisms in protein-folding diseases. Dis Model Mech 7:331-341. https://doi.org/10.1242/dmm.014589

Fiorini C et al (2008) Accelerated internalization of junctional membrane proteins (connexin 43, N-cadherin and ZO-1) within endocytic vacuoles: an early event of DDT carcinogenicity. Biochim Biophys Acta 1778:56-67. https://doi.org/10.1016/j. bbamem.2007.08.032

Francis R, Xu X, Park H, Wei CJ, Chang S, Chatterjee B, Lo C (2011) Connexin43 modulates cell polarity and directional cell migration by regulating microtubule dynamics. PLoS One 6:e26379. https:// doi.org/10.1371/journal.pone.0026379

Fritsch EB, Pessah IN (2013) Structure-activity relationship of noncoplanar polychlorinated biphenyls toward skeletal muscle ryanodine receptors in rainbow trout (Oncorhynchus mykiss). Aquat Toxicol 140-141:204-212. https://doi.org/10.1016/j. aquatox.2013.06.003
Fushiki S, Perez Velazquez JL, Zhang L, Bechberger JF, Carlen PL, Naus CC (2003) Changes in neuronal migration in neocortex of connexin43 null mutant mice. J Neuropathol Exp Neurol 62:304-314

Garrison PM, Tullis K, Aarts JM, Brouwer A, Giesy JP, Denison MS (1996) Species-specific recombinant cell lines as bioassay systems for the detection of 2,3,7,8-tetrachlorodibenzo-p-dioxin-like chemicals. Fundam Appl Toxicol 30:194-203

Giepmans BN, Moolenaar WH (1998) The gap junction protein connexin43 interacts with the second PDZ domain of the zona occludens-1 protein. Curr Biol 8:931-934

Groothuis FA, Heringa MB, Nicol B, Hermens JL, Blaauboer BJ, Kramer NI (2015) Dose metric considerations in in vitro assays to improve quantitative in vitro-in vivo dose extrapolations. Toxicology 332:30-40. https://doi.org/10.1016/j.tox.2013.08.012

Guan X, Ruch RJ (1996) Gap junction endocytosis and lysosomal degradation of connexin43-P2 in WB-F344 rat liver epithelial cells treated with DDT lindane. Carcinogenesis 17:1791-1798

Guo Y, Martinez-Williams C, Rannels DE (2003) Gap junctionmicrotubule associations in rat alveolar epithelial cells. Am J Physiol Lung Cell Mol Physiol 285:L1213-L1221. https://doi. org/10.1152/ajplung.00066.2003

Hamers $\mathrm{T}$ et al (2011) In vitro toxicity profiling of ultrapure nondioxin-like polychlorinated biphenyl congeners and their relative toxic contribution to PCB mixtures in humans. Toxicol Sci 121:88-100. https://doi.org/10.1093/toxsci/kfr043

Hauser MA, Legler DF (2016) Common and biased signaling pathways of the chemokine receptor CCR7 elicited by its ligands CCL19 and CCL21 in leukocytes. J Leukoc Biol 99:869-882. https://doi. org/10.1189/jlb.2MR0815-380R

Hauser MA et al (2016) Inflammation-induced CCR7 oligomers form scaffolds to integrate distinct signaling pathways for efficient cell. Migr Immunity 44:59-72. https://doi.org/10.1016/j. immuni.2015.12.010

Hemming H, Warngard L, Ahlborg UG (1991) Inhibition of dye transfer in rat liver WB cell culture by polychlorinated biphenyls. Pharmacol Toxicol 69:416-420

Henry TR, DeVito MJ (2003) Non-dioxin-like PCBs: effects and consideration in ecological risk assessment. Ecological Risk Assessment Support Center, Office of Research and Development, US Environmental Protection Agency

Hestermann EV, Stegeman JJ, Hahn ME (2000) Relative contributions of affinity and intrinsic efficacy to aryl hydrocarbon receptor ligand potency. Toxicol Appl Pharmacol 168:160-172. https://doi. org/10.1006/taap.2000.9026

Huang GY, Cooper ES, Waldo K, Kirby ML, Gilula NB, Lo CW (1998) Gap junction-mediated cell-cell communication modulates mouse neural crest migration. J Cell Biol 143:1725-1734

Hunter AW, Barker RJ, Zhu C, Gourdie RG (2005) Zonula occludens-1 alters connexin 43 gap junction size and organization by influencing channel accretion. Mol Biol Cell 16:5686-5698. https://doi. org/10.1091/mbc.E05-08-0737

Jacobson JL, Jacobson SW (1996) Intellectual impairment in children exposed to polychlorinated biphenyls in utero. N Engl J Med 335:783-789. https://doi.org/10.1056/NEJM199609123351104

Jacobson JL, Jacobson SW, Humphrey HE (1990) Effects of exposure to PCBs and related compounds on growth and activity in children. Neurotoxicol Teratol 12:319-326

Jensen AA (1989) Background levels in humans. In: Kimbrough RD, Jensen AA (eds) Halogenated biphenyls, terphenyls, naphthalenes, dibenzodioxins and related products. Elsevier Science Publishers, Amsterdam, The Netherlands, pp 345-364

Kang KS, Wilson MR, Hayashi T, Chang CC, Trosko JE (1996) Inhibition of gap junctional intercellular communication in normal human breast epithelial cells after treatment with pesticides, 
PCBs, and PBBs, alone or in mixtures. Environ Health Perspect 104:192-200

Kang K et al (2015) Tissue-based metabolic labeling of polysialic acids in living primary hippocampal neurons. Proc Natl Acad Sci USA 112:E241-E248. https://doi.org/10.1073/pnas.1419683112

Kato Y, Kenne K, Haraguchi K, Masuda Y, Kimura R, Warngard L (1998) Inhibition of cell-cell communication by methylsulfonyl metabolites of polychlorinated biphenyl congeners in rat liver epithelial IAR 20 cells. Arch Toxicol 72:178-182

Kodavanti PR (2005) Neurotoxicity of persistent organic pollutants: possible mode(s) of action and further considerations. Dose Response 3:273-305. https://doi.org/10.2203/ dose-response.003.03.002

Krug AK, Balmer NV, Matt F, Schonenberger F, Merhof D, Leist M (2013) Evaluation of a human neurite growth assay as specific screen for developmental neurotoxicants. Arch Toxicol 87:2215-2231. https://doi.org/10.1007/s00204-013-1072-y

Laird DW (2005) Connexin phosphorylation as a regulatory event linked to gap junction internalization and degradation. Biochim Biophys Acta 1711:172-182. https://doi.org/10.1016/j. bbamem.2004.09.009

Laird DW, Castillo M, Kasprzak L (1995) Gap junction turnover, intracellular trafficking, and phosphorylation of connexin43 in brefeldin A-treated rat mammary tumor cells. J Cell Biol 131:1193-1203

Langlois S, Cowan KN, Shao Q, Cowan BJ, Laird DW (2010) The tumor-suppressive function of Connexin43 in keratinocytes is mediated in part via interaction with caveolin-1. Cancer Res 70:4222-4232. https://doi.org/10.1158/0008-5472. CAN-09-3281

Lecanda F, Warlow PM, Sheikh S, Furlan F, Steinberg TH, Civitelli R (2000) Connexin43 deficiency causes delayed ossification, craniofacial abnormalities, and osteoblast dysfunction. J Cell Biol 151:931-944

Leist M, Efremova L, Karreman C (2010) Food for thought ... considerations and guidelines for basic test method descriptions in toxicology. ALTEX 27:309-317

Leist M et al. (2017) Adverse outcome pathways: opportunities, limitations and open questions Arch Toxicol. https://doi.org/10.1007/ s00204-017-2045-3

Lemcke H, Nittel ML, Weiss DG, Kuznetsov SA (2013) Neuronal differentiation requires a biphasic modulation of gap junctional intercellular communication caused by dynamic changes of connexin43 expression. Eur J Neurosci 38:2218-2228. https://doi. org/10.1111/ejn.12219

Li J, Habbes HW, Eiberger J, Willecke K, Dermietzel R, Meier C (2007) Analysis of connexin expression during mouse Schwann cell development identifies connexin29 as a novel marker for the transition of neural crest to precursor cells. Glia 55:93-103. https://doi.org/10.1002/glia.20427

Machala M, Blaha L, Vondracek J, Trosko JE, Scott J, Upham BL (2003) Inhibition of gap junctional intercellular communication by noncoplanar polychlorinated biphenyls: inhibitory potencies and screening for potential mode(s) of action. Toxicol Sci 76:102111. https://doi.org/10.1093/toxsci/kfg209

Mariussen E, Andersson PL, Tysklind M, Fonnum F (2001) Effect of polychlorinated biphenyls on the uptake of dopamine into rat brain synaptic vesicles: a structure-activity study. Toxicol Appl Pharmacol 175:176-183. https://doi.org/10.1006/taap.2001.9231

Matesic DF, Rupp HL, Bonney WJ, Ruch RJ, Trosko JE (1994) Changes in gap-junction permeability, phosphorylation, and number mediated by phorbol ester and non-phorbol-ester tumor promoters in rat liver epithelial cells. Mol Carcinog 10:226-236

Niederwieser A, Spate AK, Nguyen LD, Jungst C, Reutter W, Wittmann V (2013) Two-color glycan labeling of live cells by a combination of Diels-Alder and click chemistry. Angew Chem Int Ed Engl 52:4265-4268. https://doi.org/10.1002/anie.201208991

Nyffeler $J$ et al. (2017a) Combination of multiple neural crest migration assays to identify environmental toxicants from a proof-ofconcept chemical library. Arch Toxicol. https://doi.org/10.1007/ s00204-017-1977-y

Nyffeler J, Karreman C, Leisner H, Kim YJ, Lee G, Waldmann T, Leist M (2017b) Design of a high-throughput human neural crest cell migration assay to indicate potential developmental toxicants. ALTEX 34:75-94. https://doi.org/10.14573/altex.1605031

Pallocca $G$ et al. (2017) Impairment of human neural crest cell migration by prolonged exposure to interferon-beta. Arch Toxicol. https://doi.org/10.1007/s00204-017-1966-1

Pau G, Fuchs F, Sklyar O, Boutros M, Huber W (2010) EBImagean $\mathrm{R}$ package for image processing with applications to cellular phenotypes. Bioinformatics 26:979-981. https://doi.org/10.1093/ bioinformatics/btq046

Pessah IN et al (2006) Structure-activity relationship for noncoplanar polychlorinated biphenyl congeners toward the ryanodine receptor-Ca2 + channel complex type 1 (RyR1). Chem Res Toxicol 19:92-101. https://doi.org/10.1021/tx050196m

Pierucci F et al (2017) Non-dioxin-like organic toxicant PCB153 modulates sphingolipid metabolism in liver progenitor cells: its role in Cx43-formed gap junction impairment. Arch Toxicol 91:749-760. https://doi.org/10.1007/s00204-016-1750-7

Prescher JA, Bertozzi CR (2005) Chemistry in living systems. Nat Chem Biol 1:13-21. https://doi.org/10.1038/nchembio0605-13

Qin H, Shao Q, Igdoura SA, Alaoui-Jamali MA, Laird DW (2003) Lysosomal and proteasomal degradation play distinct roles in the life cycle of $\mathrm{Cx} 43$ in gap junctional intercellular communication-deficient and -competent breast tumor cells. J Biol Chem 278:30005-30014. https://doi.org/10.1074/jbc.M300614200

R Core Team (2015) R: a language and environment for statistical computing. R Foundation for Statistical Computing, Vienna

Rhee DY, Zhao XQ, Francis RJ, Huang GY, Mably JD, Lo CW (2009) Connexin 43 regulates epicardial cell polarity and migration in coronary vascular development. Development 136:3185-3193. https://doi.org/10.1242/dev.032334

Ritz C, Streibig JC (2005) Bioassay analysis using R. J Stat Softw 12:1-22

Ruangvoravat CP, Lo CW (1992) Connexin 43 expression in the mouse embryo: localization of transcripts within developmentally significant domains. Dev Dyn 194:261-281. https://doi.org/10.1002/ aja.1001940403

Safe SH (1994) Polychlorinated biphenyls (PCBs): environmental impact, biochemical and toxic responses, and implications for risk assessment. Crit Rev Toxicol 24:87-149. https://doi. org/10.3109/10408449409049308

Schalper KA, Carvajal-Hausdorf D, Oyarzo MP (2014) Possible role of hemichannels in cancer. Front Physiol 5:237. https://doi. org/10.3389/fphys.2014.00237

Shain W, Bush B, Seegal R (1991) Neurotoxicity of polychlorinated biphenyls: structure-activity relationship of individual congeners. Toxicol Appl Pharmacol 111:33-42

Simeckova P, Vondracek J, Andrysik Z, Zatloukalova J, Krcmar P, Kozubik A, Machala M (2009) The 2,2',4,4',5,5'-hexachlorobiphenyl-enhanced degradation of connexin 43 involves both proteasomal and lysosomal activities. Toxicol Sci 107:9-18. https:// doi.org/10.1093/toxsci/kfn202

Sonneveld E, Jansen HJ, Riteco JA, Brouwer A, van der Burg B (2005) Development of androgen- and estrogen-responsive bioassays, members of a panel of human cell line-based highly selective steroid-responsive bioassays. Toxicol Sci 83:136-148. https://doi. org/10.1093/toxsci/kfi005

Stiegler NV, Krug AK, Matt F, Leist M (2011) Assessment of chemical-induced impairment of human neurite outgrowth by 
multiparametric live cell imaging in high-density cultures. Toxicol Sci 121:73-87. https://doi.org/10.1093/toxsci/kfr034

Tabb MM, Kholodovych V, Grun F, Zhou C, Welsh WJ, Blumberg B (2004) Highly chlorinated PCBs inhibit the human xenobiotic response mediated by the steroid and xenobiotic receptor (SXR). Environ Health Perspect 112:163-169

van der Burg B, van der Linden S, Man Hy, Winter R, Jonker L, van Vugt-Lussenburg B, Brouwer A (2013) A panel of quantitative calux $^{\circledR}$ reporter gene assays for reliable high-throughput toxicity screening of chemicals and complex mixtures high-throughput screening methods in toxicity. Testing 519-532:111853820X

van der Linden SC, von Bergh ARM, van Vught-Lussenburg BMA, Jonker LRA, Teunis M, Krul CAM, van der Burg B (2014) Development of a panel of high-throughput reporter-gene assays to detect genotoxicity and oxidative stress. Mutat Res Genet Toxicol Environ Mutagenes 760:23-32\%@1383-5718

van der Burg B et al (2015) A high throughput screening system for predicting chemically-induced reproductive organ deformities. Reprod Toxicol 55:95-103. https://doi.org/10.1016/j. reprotox.2014.11.011

Wassermann M, Wassermann D, Cucos S, Miller HJ (1979) World PCBs map: storage and effects in man and his biologic environment in the 1970s. Ann N Y Acad Sci 320:69-124\%@ 1749-6632

Westerink RH (2014) Modulation of cell viability, oxidative stress, calcium homeostasis, and voltage- and ligand-gated ion channels as common mechanisms of action of (mixtures of) non-dioxin-like polychlorinated biphenyls and polybrominated diphenyl ethers. Environ Sci Pollut Res Int 21:6373-6383. https://doi.org/10.1007/ s11356-013-1759-x

Wiencken-Barger AE, Djukic B, Casper KB, McCarthy KD (2007) A role for Connexin43 during neurodevelopment. Glia 55:675-686. https://doi.org/10.1002/glia.20484

Wigestrand MB, Stenberg M, Walaas SI, Fonnum F, Andersson PL (2013) Non-dioxin-like PCBs inhibit [(3)H]WIN-35,428 binding to the dopamine transporter: a structure-activity relationship study. Neurotoxicology 39:18-24. https://doi.org/10.1016/j. neuro.2013.07.005

Willebrords J, Maes M, Yanguas SC, Vinken M (2017) Inhibitors of connexin and pannexin channels as potential therapeutics. Pharmacol Ther. https://doi.org/10.1016/j.pharmthera.2017.07.001

World Health Organization (2000) Air quality guidelines for Europe. WHO Regional Publications, Copenhagen, Denmark

$\mathrm{Xu} X$ et al (2001) Modulation of mouse neural crest cell motility by $\mathrm{N}$-cadherin and connexin 43 gap junctions. J Cell Biol 154:217-230

Xu X, Francis R, Wei CJ, Linask KL, Lo CW (2006) Connexin 43-mediated modulation of polarized cell movement and the directional migration of cardiac neural crest cells. Development 133:3629-3639. https://doi.org/10.1242/dev.02543

Yeakley JM, Shepard PJ, Goyena DE, VanSteenhouse HC, McComb JD, Seligmann BE (2017) A trichostatin A expression signature identified by TempO-Seq targeted whole transcriptome profiling. PLoS One 12:e0178302. https://doi.org/10.1371/journal. pone. 0178302

Ziegler S et al (2017) Accelerated telomere shortening in peripheral blood lymphocytes after occupational polychlorinated biphenyls exposure. Arch Toxicol 91:289-300. https://doi.org/10.1007/ s00204-016-1725-8

Zimmer B, Lee G, Balmer NV, Meganathan K, Sachinidis A, Studer L, Leist M (2012) Evaluation of developmental toxicants and signaling pathways in a functional test based on the migration of human neural crest cells. Environ Health Perspect 120:11161122. https://doi.org/10.1289/ehp.1104489

Zimmer B et al (2014) Profiling of drugs and environmental chemicals for functional impairment of neural crest migration in a novel stem cell-based test battery. Arch Toxicol 88:1109-1126. https://doi. org/10.1007/s00204-014-1231-9 